\title{
Nonalcoholic fatty liver disease in CLOCK mutant mice
}

\author{
Xiaoyue Pan, ${ }^{1,2}$ Joyce Queiroz, ${ }^{1}$ and M. Mahmood Hussain ${ }^{1,2,3}$ \\ 'Department of Cell Biology, SUNY Downstate Medical Center, Brooklyn, New York, USA. ²Department of Foundations of Medicine, NYU Long Island School of Medicine, Mineola, New York, USA. ${ }^{3}$ VA New York \\ Harbor Healthcare System, Brooklyn, New York, USA.
}

\begin{abstract}
Nonalcoholic fatty liver disease (NAFLD) is becoming a major health issue as obesity increases around the world. We studied the effect of a circadian locomotor output cycles kaput (CLOCK) mutant ( $\mathrm{Cl}^{\mathbf{4 1 9 / 4 1 9}}$ ) protein on hepatic lipid metabolism in C57BL/6 Clk ${ }^{\mathrm{wt} / \mathrm{wt}}$ and apolipoprotein E-deficient $\left(A p o e^{-/-}\right.$) mice. Both $\mathrm{Cl}^{419 / 419}$ and $\mathrm{Cl}^{419 / 419} \mathrm{Apoe}^{-/-}$mice developed a full spectrum of liver diseases (steatosis, steatohepatitis, cirrhosis, and hepatocellular carcinoma) recognized in human NAFLD when challenged with a Western diet, lipopolysaccharide, or $\mathrm{CoCl}_{2}$. We identified induction of CD36 and hypoxiainducible factor $1 \alpha$ (HIF1 $\alpha$ ) proteins as contributing factors for NAFLD. Mechanistic studies showed that WT CLOCK protein interacted with the E-box enhancer elements in the promoters of the proline hydroxylase domain (PHD) proteins to increase

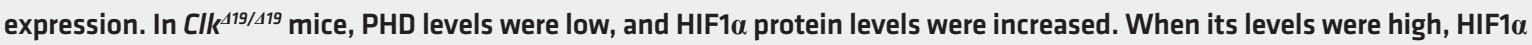
interacted with the $C d 36$ promoter to augment expression and enhance fatty acid uptake. Thus, these studies establish a regulatory link among circadian rhythms, hypoxia response, fatty acid uptake, and NAFLD. The mouse models described here may be useful for further mechanistic studies in the progression of liver diseases and in the discovery of drugs for the treatment of these disorders.
\end{abstract}

\section{Introduction}

Nonalcoholic fatty liver disease (NAFLD) encompasses a continuum of liver abnormalities, from fatty liver to steatohepatitis (NASH) with or without fibrosis, cirrhosis, and hepatocellular carcinoma (1-3). Although fatty liver is considered reversible and benign, recent studies indicate that it can advance to NASH and fibrosis (1-3). NASH can progress to cirrhosis and hepatocellular carcinoma (HCC) in many individuals. NAFLD is the most common liver disease in the Western world. The global estimated prevalence of NAFLD is approximately $25 \%$ and is expected to increase in the future along with increases in metabolic disorders, such as metabolic syndrome, obesity, and diabetes $(1,2)$. The pathogenesis of NAFLD has long been modeled on a 2-hit theory of lipid accumulation followed by induction of inflammation; however, according to the new multiple-hit theory, it is clear that the pathogenesis of this disease is more complex and that multiple molecular pathways independently contribute to NAFLD (3).

A primary cause of NAFLD is deregulation of fatty acid metabolism involving increased de novo lipogenesis and reduced $\beta$-oxidation. Derangements in several other metabolic pathways, such as bile acid fluxes, immune/inflammatory responses, autophagy, and host-gut microbiota interactions, also contribute to NAFLD pathogenesis (1-3). Many of these pathways of bile acid fluxes, autophagy, and inflammation show circadian rhythmicity. Other factors, such as microbiota and high-fat diets, affect circadian circuitry. Therefore, chronodisruption may play a role in liver steatosis $(4,5)$. Circadian rhythms are controlled by few

Conflict of interest: The authors have declared that no conflict of interest exists. Copyright: () 2020, American Society for Clinical Investigation.

Submitted: August 16, 2019; Accepted: May 5, 2020; Published: July 13, 2020.

Reference information: J Clin Invest. 2020;130(8):4282-4300.

https://doi.org/10.1172/JCl132765. core transcription factors: circadian locomotor output cycles kaput (CLOCK), brain and muscle aryl hydrocarbon receptor nuclear translocator-like 1 (BMAL1), periods (PER1-3), and cryptochromes (CRY1 and CRY2). Early studies in CLOCK mutant $\left(C l k^{419 / 419}\right)$ mice expressing a dominant-negative CLOCK transcription factor with abnormal circadian rhythms showed that these mice develop steatosis (6); however, biochemical and molecular mechanisms were not explored.

Under hypoxic conditions, hypoxia-inducible factor $1 \alpha$ (HIF1 $\alpha$ ) orchestrates a major adaptive response (7-10). Under normoxic conditions, the HIF1 $\alpha$ protein undergoes oxygendependent prolyl hydroxylation by proline hydroxylase domain proteins 1, 2, and 3 (PHD1, PHD2, and PHD3) and is degraded by proteasomes $(8,9,11)$. Under hypoxic conditions, HIF1 $\alpha$ does not undergo proline hydroxylation and is not degraded, so cellular HIF $1 \alpha$ concentrations increase. HIF1 $\alpha$ then heterodimerizes with HIF1 $\beta$ and interacts with hypoxia response elements in several target gene promoters to increase gene expression - promoting angiogenesis and glycolysis and preventing cell proliferation (7). HIF1 $\alpha$ and HIF1 $\beta$ are structurally similar to CLOCK and BMAL1, and their recognition sequences are very similar $(12,13)$. Hypoxia signaling and circadian CLOCK reciprocally regulate each other under hypoxic conditions $(12,14)$. However, the role of HIF1 $\alpha$ in normoxic condition is unknown.

Here, we studied the development of liver diseases in $C l k^{419 / 419}$ mice bred on C57BL/6 WT ( $\left.C l k^{w t / w t}\right)$ and apolipoprotein E-deficient $\left(\right.$ Apo $\left.^{-/-}\right)$backgrounds to identify mechanisms that contribute to NAFLD. Our studies show that $C k^{419 / 419}$ mice develop different liver diseases, from hepatosteatosis to HCC, when subjected to environmental insults. At the mechanistic level, we demonstrate that disruptions in circadian rhythms induce hypoxia response factors and fatty acid uptake contributing to the pathogenesis of NAFLD. 


\section{Results}

Clk $k^{419 / 419}$ mice develop steatosis and steatohepatitis with age on a chow diet when compared with $C l k^{w t / w t}$ mice. We previously showed that $C l k^{419 / \Delta 19}$ mice fed chow and Western diets produce more lipoproteins and have higher plasma triglycerides than $C l k^{w t / w t}$ control mice (15). Here, we studied changes in hepatic lipids in $C l k^{419 / 419}$ mice fed a chow diet and compared them with their $C l k^{w t / w t}$ siblings. $C l k^{419 / \Delta 19}$ mice gained more weight than controls with age (Supplemental Figure 1A; supplemental material available online with this article; https://doi.org/10.1172/JCI132765DS1). Oil Red O staining showed increased hepatosteatosis in $\mathrm{Clk}^{419 / 419}$ mice compared with $C l k^{w t / w t}$ controls (Supplemental Figure 2A). Although hepatic triglyceride levels were not different in $C l k^{w t / w t}$ and $C l k^{419 / \Delta 19}$ mice at 1 or 3 months of age, $C l k^{419 / \Delta 19}$ mice on a chow diet accumulated more hepatic triglycerides than $C l k^{w t / w t}$ mice did at 6 and 10 months of age (Supplemental Figure 2B). Plasma alanine aminotransferase (ALT) levels were similar in $C l k^{w t / w t}$ and Clk $k^{119 / 419}$ mice until 6 months; however, 10-month-old $C l k^{419 / 419}$ mice had significantly higher plasma ALT levels, indicating liver damage (Supplemental Figure 2C). Livers of 3- to 10-month-old $C l k^{419 / 419}$ mice took up more intraperitoneally injected (i.p.-injected) $\left[{ }^{3} \mathrm{H}\right]$-labeled oleic acid (OA) than $C l k^{w t / w t}$ mice (Supplemental Figure 2D). These studies indicate that $C l k^{119 / 419}$ livers take up more fatty acids, accumulate higher amounts of triglycerides, and develop hepatosteatosis with age on chow diet.

To discover factors contributing to age-dependent changes in the livers of $C l k^{119 / 419}$ mice, we measured candidate genes involved in 4 different pathways: lipid metabolism, endoplasmic reticulum (ER) stress, inflammatory response, and cancer. Significant upregulation of genes involved in lipid uptake (Cd36), lipid synthesis (Dgat2, Fas, Srebp1c), and lipoprotein assembly (Mttp) and significant downregulation of genes involved in fatty acid oxidation (Cpt1 and Ppara) were seen in 3-month-old $C l k^{119 / 419}$ versus $C l k^{w t / w t}$ mice (Supplemental Figure 2E). Fold changes in these genes were more prominent at 12 months. Ppary and Pgc1 $\alpha$ levels did not change. No significant changes were noted in the expression of genes in inflammatory response, ER stress, or cancer in 3-month-old Clk $k^{119 / 419}$ mice (Supplemental Figure 2, F-H). However, significant changes were observed in the expression of genes involved in these pathways in 12-month-old Clk ${ }^{119 / 419}$ mice (Supplemental Figure 2, F-H). At 12 months, expression of Ire1 $\alpha, X b p 1$, and Atf 4 increased, suggesting induction of ER stress. Increases in Tnfo, Il6, monocyte chemoattractant protein-1 (Mcp1), and Cd68 mRNAs suggest macrophage infiltration and an inflammatory response. Increases in $M d m 2$ and decreases in Trp53 expression reflect increased susceptibility to carcinogenesis. These studies indicated that changes in lipid metabolism gene expression precede changes in other pathways in $C l k^{119 / 419}$ mice.

Accelerated hepatosteatosis in Clk ${ }^{119 / 419}$ mice fed cholate-containing high-fat and Western diets. We then asked how different dietary insults affect the progression of hepatosteatosis. Male 3-month-old $C l k^{419 / 419}$ mice fed a cholate-containing high-fat diet for 2 months were leaner (Supplemental Figure 1B) and developed hepatomegaly and had grossly enlarged livers compared with $C l k^{w t / w t}$ mice (Supplemental Figure 2I, top). Macrovesicular steatohepatitis was evident in the livers of $C l k^{419 / 419}$ mice after Oil Red O staining (Supplemental Figure 2I, bottom). The liver/body weight ratio was significant- ly higher in $C l k^{119 / \Delta 19}$ than in $C l k^{w t / w t}$ mice (Supplemental Figure 2J) because of increases in liver weights (not shown) and decreases in total body weights (Supplemental Figure 1B). Quantitative analyses revealed higher levels of triglyceride and thiobarbituric acid-reactive substances (TBARS), indicators of oxidized lipids, in the livers of $C l k^{419 / 419}$ mice (Supplemental Figure 2K). In addition, $C l k^{119 / 419}$ mice showed several-fold increases in plasma ALT and aspartate aminotransferase (AST) levels (Supplemental Figure 2L), indicating significant liver dysfunction. Livers of $C^{1419 / 419}$ mice took up more i.p.-injected fatty acids (Supplemental Figure $2 \mathrm{M})$. Hence, $\mathrm{Clk}^{419 / 419}$ mice on a cholate-containing high-fat diet developed more hepatosteatosis in 2 months than did Clkwt/wt mice.

Next, 3-month-old male Clk $k^{w t / w t}$ and $C l k^{119 / 419}$ mice were fed a high-cholesterol, high-fat Western diet for 2 months. $C l k^{119 / \Delta 19}$ mice were heavier (Supplemental Figure 1C), had higher amounts of hepatic triglyceride (Supplemental Figure 2N) and TBARS (Supplemental Figure 2O), and had increased plasma ALT levels (Supplemental Figure 2P) compared with $C l k^{w t / w t}$ controls. Macrovesicular steatohepatitis was evident after Oil Red O staining (Supplemental Figure 2Q). Further, $C l k^{419 / 419}$ mice took up more i.p.-injected $\left[{ }^{3} \mathrm{H}\right] \mathrm{OA}$ (Supplemental Figure 2R). Ex vivo studies with liver slices showed increased fatty acid uptake and reduced fatty acid oxidation (Supplemental Figure 2S). Expression of genes in fatty acid uptake (Cd36), lipid synthesis (Dgat2, Ppary), and lipoprotein secretion (Mttp) increased in $C l k^{119 / 419}$ compared with $C l k^{w t / w t}$ mice (Supplemental Figure 2T). Expression of Ppara and Cpt1a, involved in fatty acid oxidation, were decreased. Livers of $C l k^{119 / 419}$ mice had higher levels of mRNA involved in the inflammatory response. Analyses of ER stress response genes showed significant increases in Ire1 $\alpha, X b p 1$, and Atf4 in Clk $k^{419 / 419}$ mice. Genes involved in cancer progression were unaltered, except for some decrease in Trp53, in Clk ${ }^{119 / 419}$ mice compared with controls. Thus, a Western diet induces steatosis, ER stress, and an inflammatory response but does not affect cancer genes in $C l k^{419 / \Delta 19}$ mice.

CLOCK regulates $C D 36$ in liver-derived cells by regulating $P H D$ proteins and HIF1 $\alpha$. The above studies indicated that the earliest response in chow-fed $C l^{419 / 419}$ mice was upregulation of genes in lipid uptake, lipogenesis, and lipoprotein assembly (Supplemental Figure 2E). We previously elucidated mechanisms in the regulation of Mttp by CLOCK and BMAL1 $(16,17)$. Here, we concentrated on the mechanisms by which CLOCK regulates CD36. First, we hypothesized that upregulation of Srebp1c might be responsible for increased CD36 expression. Small interfering (si) CLOCK (siClk) in human hepatoma Huh7 cells and mouse primary hepatocytes had no effect on Srebp1c mRNA levels (Supplemental Figure 3, A and B). Furthermore, approximately $80 \%$ knockdown of Srebp1c had no effect on Cd36 mRNA in Huh7 and primary mouse hepatocytes (Supplemental Figure 3, C and D). Thus, changes in Cd36 mRNA are unrelated to changes in Srebp1c expression in $\mathrm{Clk}^{119 / 419}$ mice. We previously showed that $S h p, U s f 2$, and Gata4 are involved in the regulation of $M t t p, A b c a 1$, and $A b c g 5 / g 8$, respectively (15-17). Knockdown of these genes had no effect on $C d 36$ mRNA (Supplemental Figure 3E). Therefore, we looked for other genes that might be involved in the regulation of CD36. Hypoxia and HIF1 $\alpha$ regulate CD36 expression in macrophages and in corneal and retinal tissues (18-20). We asked whether HIF1 $\alpha$ could regulate CD36 in liver-derived cells under normoxic conditions. 
A
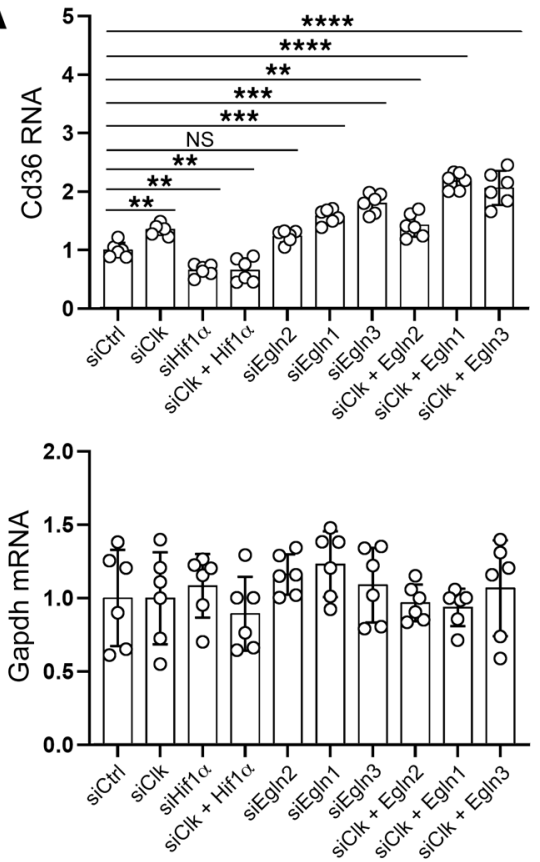

B

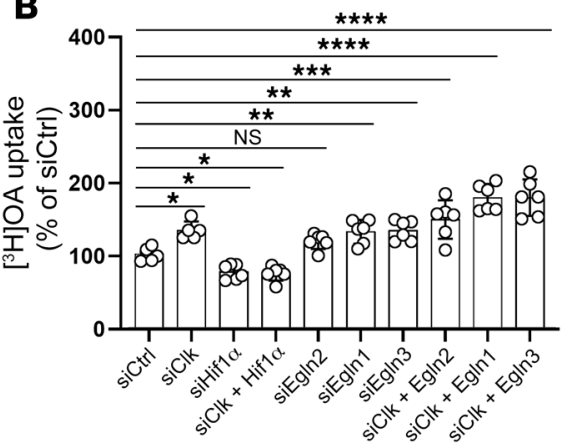

C

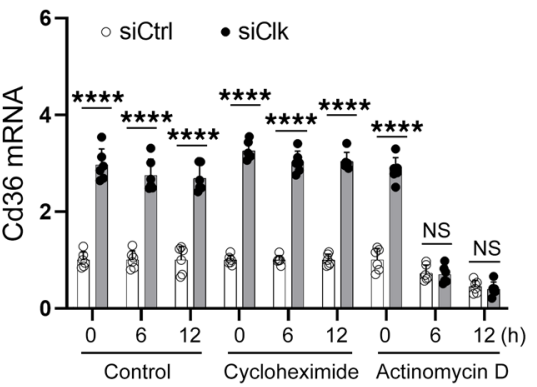

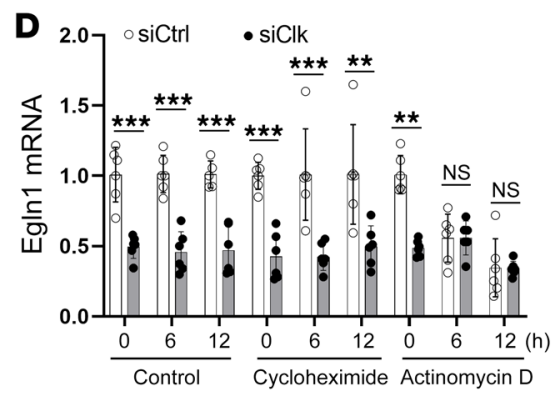

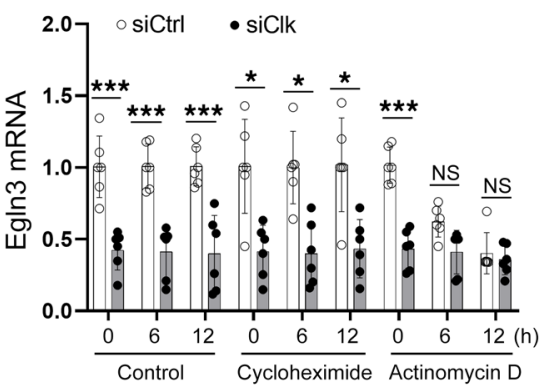

E

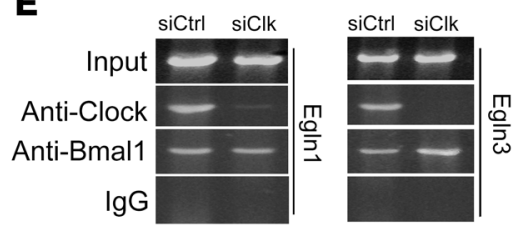

$\mathbf{F}$

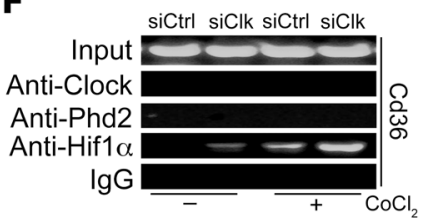

G

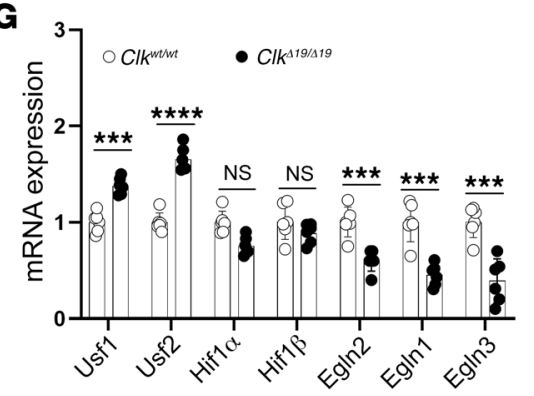

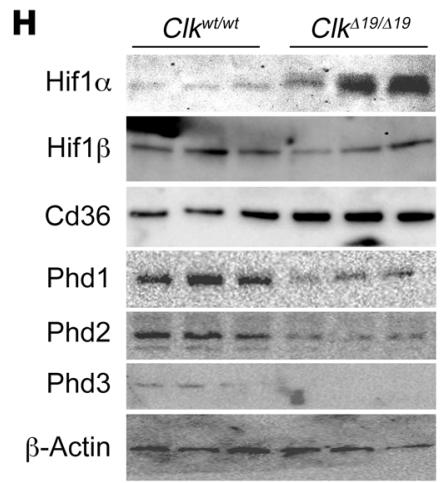

I

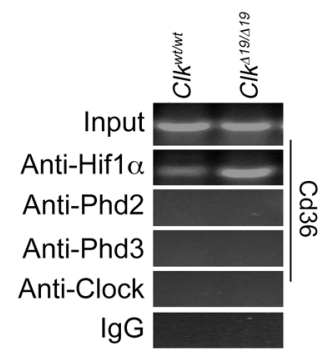

$J$

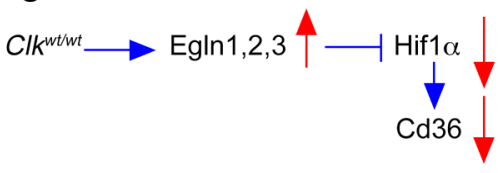

K

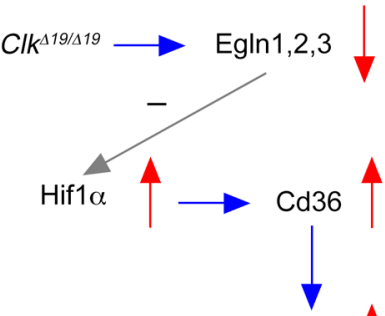

Fatty acid uptake<smiles>C[Al](N)/N=C\I</smiles>

Figure 1. CLOCK regulates PHD proteins and HIF1 $\alpha$ to regulate CD36. (A-F) Primary hepatocytes from WT chow-fed mice were used for these studies. (A and B) Hepatocytes were transfected in triplicate with indicated siRNAs, and Cd36 (top) and Gapdh (bottom) mRNA levels were measured after 72 hours. (B) After 72 hours, cells were incubated with $0.5 \mu \mathrm{Ci}$ of [ $\left.{ }^{3} \mathrm{H}\right] \mathrm{OA}$. After 1 hour, cells were washed, and radioactivity was quantified. (C and $\left.\mathbf{D}\right)$ Primary hepatocytes were transfected in triplicate with siCtrl or siClk for 72 hours and treated with cycloheximide $(20 \mu \mathrm{M})$ or actinomycin $\mathrm{D}(2 \mu \mathrm{M})$ for 6 or 12 hours. Cd36 (C) or $E g \ln 2$ and $E g \ln 3$ (D) mRNA levels were quantified. Data are representative of 3 experiments; mean $\pm \mathrm{SD} ;{ }^{*} P<0.05,{ }^{* *} P<0.01,{ }^{* * *} P<0.001,{ }^{* * * *} P$ $<0.0001$; multiple-comparisons 1-way ANOVA. (E) Hepatocytes were transfected with siClk or siCtrl. After 72 hours, ChIP was performed using indicated antibodies to amplify E-boxes (Supplemental Figure 5B) in Egln1 and Egln3 promoters. Data are representative of 2 experiments. (F) Hepatocytes transfected with siClk or siCtrl for 48 hours were treated with or without $\mathrm{CoCl}_{2}$ for 12 hours and used for ChIP to study the binding of HIF1 (Supplemental Figure 5C) in the Cd36 promoter. Data are representative of 2 independent experiments. ( $\mathbf{G}$ and $\mathbf{H}$ ) Livers from chow-fed, male, 10-month-old Clk ${ }^{419 / 419}$ and $C l k^{w t / w t}$ mice ( $n=5$ per group) were used to measure mRNA (G) (mean $\pm \mathrm{SD}$; ${ }^{* *} P<0.001$, ${ }^{* * *} P<0.0001$, multiple $t$ tests compared with controls; representative of 2 experiments) and protein levels (H). (I) Livers from chow-fed, male, 10-month-old CIK ${ }^{419 / 419}$ and $C I k^{\text {wt/wt }}$ mice were used for ChIP; representative of 2 experiments. ( and $\mathbf{K}$ ) Schematic diagram explaining the molecular mechanisms regulating CD36 expression and OA uptake in livers of $C \mathbb{k}^{119 / 419}$ and $C \mathrm{k}^{\mathrm{wt} / \mathrm{wt}}$ mice. (J) In Cl ${ }^{\mathrm{wt} / \mathrm{wt}}$ mice, CLOCK binds to the E-boxes in the promoters of Phd genes to increase transcription and protein levels. In the presence of high PHD levels, HIF1 $\alpha$ protein is degraded. (K) In CI $\mathbf{k}^{419 / 419}$ mice, expression of PHD proteins is low and HIF1 $\alpha$ protein levels are increased. Under these conditions, HIF1 $\alpha$ binds to the $C d 36$ promoter to increase transcription and protein levels. This might be one mechanism for increased fatty acid uptake in these mice. 
siClk increased, but siHifl $\alpha$ reduced, $C d 36$ mRNA levels in mouse primary hepatocytes (Figure 1A) and in human hepatoma Huh7 cells (Supplemental Figure 4A) without affecting Gapdh mRNA levels. Further, siClk was unable to increase $C d 36$ in the presence of siHifl $\alpha$, suggesting involvement of HIF1 $\alpha$ in the regulation of CD36 by CLOCK (Figure 1A and Supplemental Figure 4A). HIF1 $\alpha$ protein levels are regulated by PHD proteins $(10,11)$. Knockdown of PHD1 (Egln2), PHD2 (Egln1), and PHD3 (Egln3) increased Cd36 expression in hepatocytes and Huh7 cells (Figure 1A and Supplemental Figure 4A). siEgln1 and siEgln3 combined with siClk increased Cd36 expression more than individual siRNA, indicating additive effects (Figure 1A and Supplemental Figure 4A). These changes in $C d 36$ mRNA levels correlated with increases and decreases in the uptake of OA in these cells (Figure $1 \mathrm{~B}$ and Supplemental Figure 4B). These studies suggest that HIF1 $\alpha$ as well as PHD2 and PHD3 proteins might be involved in the regulation of CD36 and fatty acid uptake by CLOCK. We further studied the regulation of HIF1 $\alpha$ and PHD proteins by overexpressing CLOCK in Huh7 cells (Supplemental Figure 4, C and D). CLOCK overexpression reduced OA uptake in Huh7 cells and increased mRNA levels of EGLN2, EGLN1, and EGLN3 but had no effect on HIF1a mRNA levels (Supplemental Figure 4D). These studies indicated that CLOCK increases EGLN mRNA levels and decreases hepatic fatty acid uptake.

Attempts were then made to understand transcriptional and translational mechanisms in the upregulation of HIF1 $\alpha$ and CD36 by CLOCK. Increases in Cd36 mRNA levels by siClk were unaffected by cycloheximide, a protein synthesis inhibitor, but were abrogated in the presence of actinomycin D, an inhibitor of transcription, at 6 and 12 hours compared with 0 hour (Figure $1 C)$, indicating transcriptional activation. Unlike $C d 36, E g \ln 1$ and Egln3 mRNA levels were lower in siClk-treated cells (Figure 1D). These levels were unaffected by cycloheximide. However, Egln1 and Egln 3 mRNA levels were reduced in siControl-treated (siCtrltreated) cells after actinomycin D treatment, indicating that $E g \ln 1$ and Egln3 gene transcription is high in control cells compared with siClk-treated cells because of increased transcription. Thus, CLOCK may interact with Egln1 and Egln 3 gene promoters to increase their transcription. To test this, we looked for potential enhancer boxes (E-boxes) in the Egln 1 and $E g \ln 3$ promoters (Supplemental Figure 5). Human (Supplemental Figure 5A) and mouse (Supplemental Figure 5B) Egln 1 and Egln3 promoters contain 1 to 3 E-boxes. To test whether CLOCK binds to any of these boxes, we performed chromatin immunoprecipitation (ChIP) assays and observed that both CLOCK and BMAL1 interact with Egln1 and Egln3 promoters in siCtrl-treated cells (Figure 1E). Binding of CLOCK to Egln promoters has been reported in genome-wide transcriptomic analysis (21). In our study, binding of CLOCK was abrogated in siClk-treated cells (Figure 1E). Surprisingly, BMAL1 binding was not reduced in siClk-treated cells, perhaps because BMAL1 binds to these sites, and CLOCK may interact with already-bound BMAL1 to increase transcription.

We next studied the binding of CLOCK, PHD2, and HIF1 $\alpha$ proteins to the $C d 36$ promoter; binding was undetectable in siCtrltreated hepatocytes (Figure 1F). However, binding of HIF1 $\alpha$ to the Cd36 promoter was increased in siClk-treated cells (Figure $1 \mathrm{~F}$ ). Cobalt chloride $\left(\mathrm{CoCl}_{2}\right)$, an activator of $\mathrm{HIF1} \alpha(7)$, increased the binding of HIF1 $\alpha$ to the Cd36 promoter in siCtrl- and siClk-transfected cells (Figure 1F). Thus, it is likely that CLOCK deficiency increases HIF1 $\alpha$ binding to the $\mathrm{Cd} 36$ promoter and that $\mathrm{CoCl}_{2}$ enhances this binding. This may increase CD36 protein, uptake of fatty acids, and lipid synthesis, contributing to steatosis.

Next, we asked whether these mechanisms are operative in $C l k^{419 / 419}$ mice. Egln2, Egln1, Egln3, and Hifl $\alpha$ mRNA levels showed circadian rhythms in $C l k^{w t / w t}$ mice but not in $C l k^{119 / 419}$ mice (Supplemental Figure 6). Circadian rhythms for Egln mRNAs were not in databases $(22,23)$, but Hifl $\alpha$ changes were similar to those reported in circadian rhythm gene databases (23). Clk $^{419 / 419}$ livers had lower Egln1, Egln2, and Egln3 mRNA and protein levels compared with $C l k^{w t / w t}$ controls (Figure 1, G and H). Although mRNA levels of Hifla were not different (Figure $1 G$ ), HIF1 $\alpha$ protein levels were significantly higher in $C l k^{419 / 419}$ than in $C l k^{w t / w t}$ hepatocytes (Figure $1 \mathrm{H}$ ). Similarly, CD36 protein levels were higher in $\mathrm{Clk}^{419 / 419}$ livers (Figure $1 \mathrm{H})$. ChIP assays showed that higher amounts of HIF1 $\alpha$ were associated with the $C d 36$ promoter in $C l k^{119 / 419}$ mice (Figure 1I). These studies indicated that $C l k^{419 / 419}$ livers had reduced levels of Egln mRNA but had higher levels of HIF1 $\alpha$ and CD36 proteins and that there was increased binding of HIF1 $\alpha$ to the $C d 36$ promoter. Based on these data, we propose that CLOCK interacts with E-boxes in the Egln promoters to increase PHD expression. When PHD proteins are high, HIF1 $\alpha$ levels are reduced, and binding of HIF1 $\alpha$ to the $C d 36$ promoter is reduced (Figure 1J). In $C l k^{419 / 419}$ mice, the expression of PHD proteins is reduced, HIF1 $\alpha$ protein levels are increased, and binding of HIF $1 \alpha$ to the $C d 36$ promoter is enhanced (Figure 1K). This may augment CD36 protein and uptake of fatty acids by the liver, which could contribute to steatosis.

Role of HIF1a in hepatosteatosis in chow diet-fed Clk ${ }^{419 / 419}$ mice. To further investigate whether HIF1 $\alpha$ plays a role in hepatosteatosis, we treated Western diet-fed $C l k^{419 / \Delta 19}$ and $C l k^{w t / w t}$ mice with $\mathrm{CoCl}_{2}$, a known inducer of HIF1 $\alpha$ activity (7). $\mathrm{CoCl}_{2}$-treated $\mathrm{Clk}^{119 / 419}$ mice showed significantly reduced hepatic $E g \ln 1$ and $E g \ln 3$ mRNA levels compared with $\mathrm{CoCl}_{2}$-treated $\mathrm{Clk}^{\text {wt }}{ }^{\mathrm{wt}}$ mice (Figure 2A). Although mRNA levels of Hifl $\alpha$ did not change, mRNA levels of its target gene $\operatorname{Veg} f(24,25)$ increased significantly in $\mathrm{Clk}^{119 / 419}$ mice (Figure 2A). $\mathrm{CoCl}_{2}$ treatment increased Cd36, Acc, Fas, and Srebp1c but decreased Mttp, Cpt1, and Ppar $\alpha$ mRNA levels in $C l k^{119 / \Delta 19}$ mice compared with controls (Figure $2 \mathrm{~B}$ ). $\mathrm{CoCl}_{2}$ treatment increased all inflammatory markers measured except Tlr2 (Figure 2C); enhanced ER stress markers Ire1 $\alpha, X b p 1$, and Bip without affecting Atf4 and Chop (Figure 2D); and augmented cancer markers $M d m 2$, $B c l 2$, and Bax while decreasing Trp53 in $C l k^{419 / 419}$ mice compared with controls (Figure 2E). Oil Red $\mathrm{O}$ and anti-macrophage staining showed increased lipid droplets and macrophage content, respectively, in the livers of $\mathrm{Clk}^{119 / 419}$ mice treated with $\mathrm{CoCl}_{2}$ compared with $\mathrm{Clk}^{w t / w t}$ mice (Figure $2 \mathrm{~F}$ ). $\mathrm{CoCl}_{2}$ increased hepatic triglyceride (Figure 2G) and TBARS (Figure 2H) in $C l k^{419 / 419}$ mice compared with controls. Plasma of these mice had higher ALT levels and reduced levels of $\beta$-hydroxybutyrate $\left(\beta-\mathrm{HB}\right.$ ) (Figure 2I). $\mathrm{CoCl}_{2}$ increased OA uptake by the liver in vivo (Figure 2J), in liver slices (Figure 2K), and in isolated hepatocytes (Figure 2M) of Clk $\mathrm{Cl}^{119 / \Delta 19}$ mice compared with controls. Fatty acid oxidation was reduced more in liver slices from $C l k^{419 / \Delta 19}$ mice (Figure 2L). Furthermore, increased fatty acid uptake and reduced $\beta$-oxidation were seen in Clk ${ }^{119 / 419}$ hepatocytes (Figure $2 \mathrm{~N}$ ) treated with dimethyloxalylgly- 

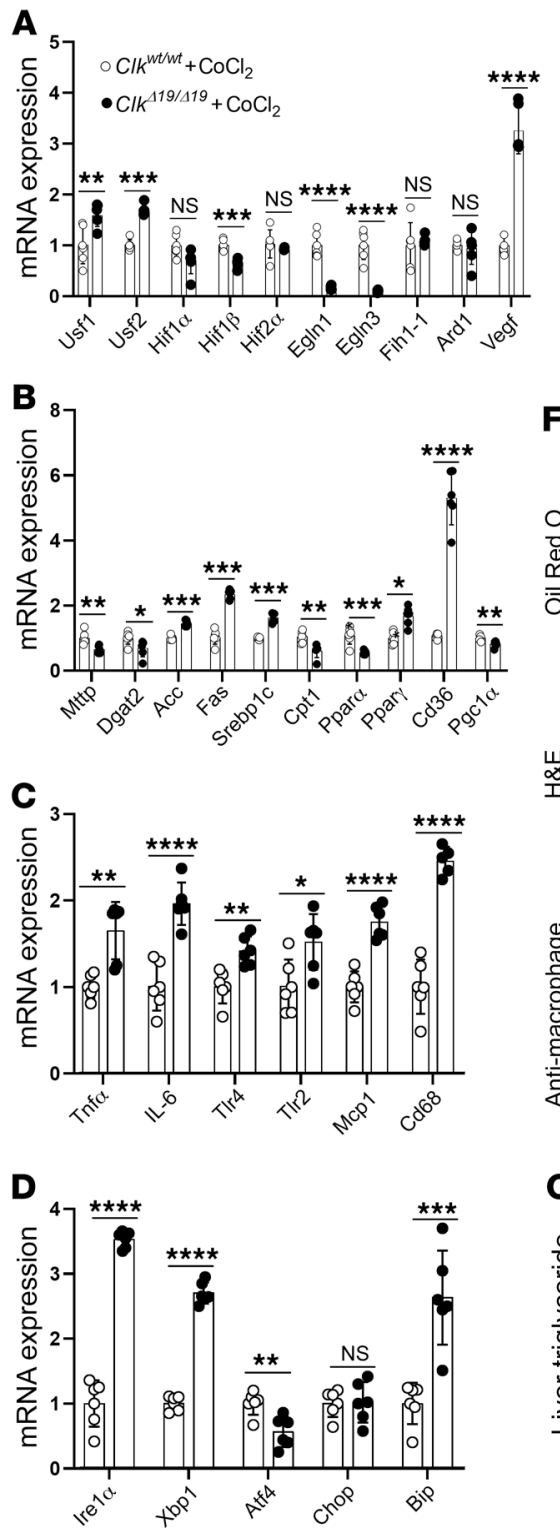

F
E
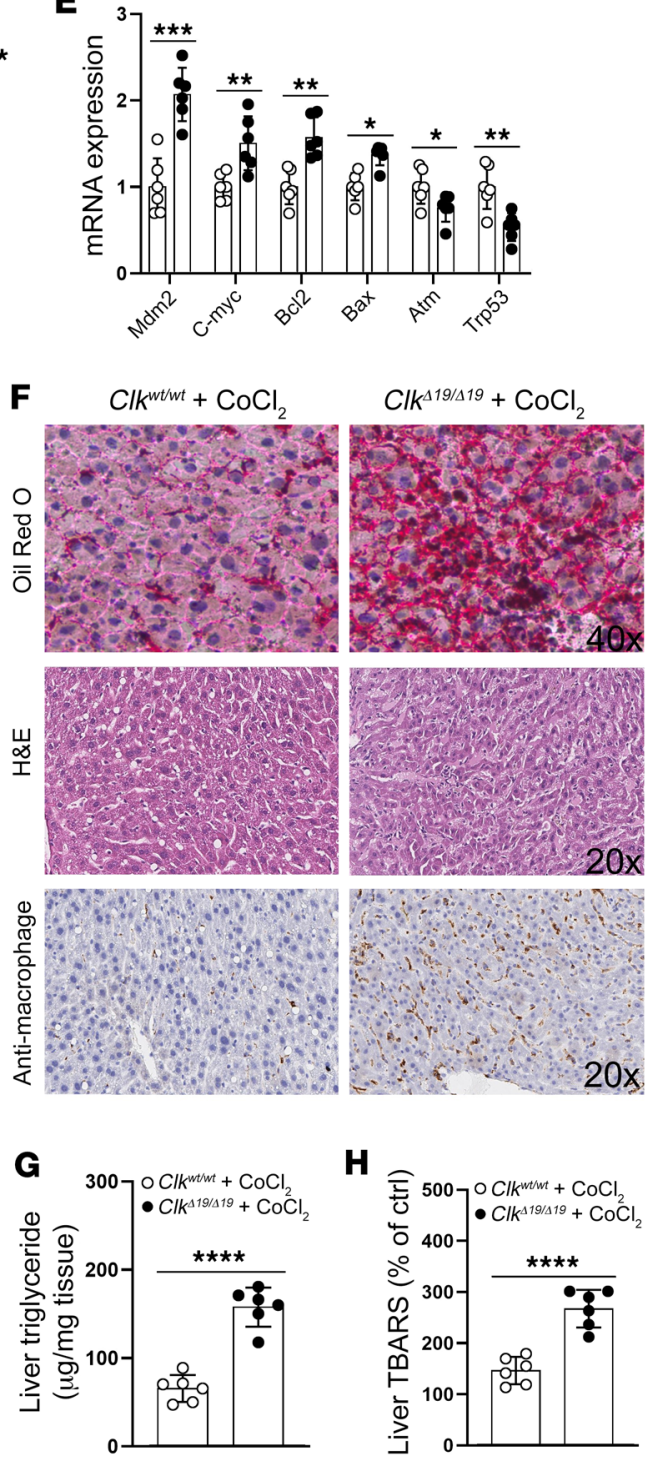
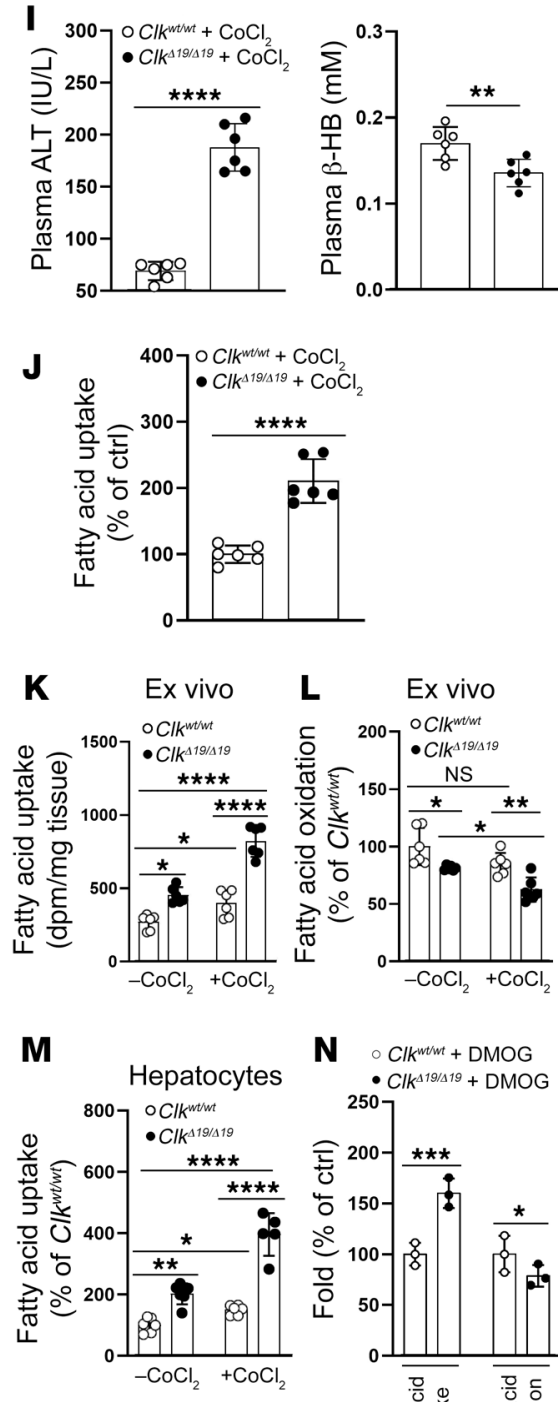

$\mathbf{C} \quad \mathrm{Cl}^{\mathrm{wtwt}}+\mathrm{DMOG}$
$\cdot \mathrm{Cl}^{\Delta 19 / \Delta 19}+\mathrm{DMOG}$ 
Figure 2. Hepatosteatosis in $\mathrm{Cl}^{419 / 419}$ mice challenged with $\mathrm{CoCl}_{2}$. Male (8-month-old) $\mathrm{Cl}^{\Delta 19 / \Delta 19}$ and $C \mathrm{~K}^{\mathrm{wt} / \mathrm{wt}}$ mice fed a Western diet for 2 months were injected i.p. 3 times with $30 \mathrm{mg} / \mathrm{kg} \mathrm{CoCl}$ on alternate days, and continued on the same diet ad libitum for 2 months. Mice were used for tissue analysis ( $n=6$ per group) or to study hepatic uptake of $\left[{ }^{3} \mathrm{H}\right] \mathrm{OA}(n=5-6$ per group). (A-E) Livers were used to measure mRNA levels. Mean \pm SD; ${ }^{*} P<0.05,{ }^{* *} P<0.01,{ }^{* *} P<0.001,{ }^{* * *} P<0.0001$, multiple $t$ tests. (F) Frozen liver sections were used for Oil Red $0, \mathrm{H} \& \mathrm{E}$, and anti-macrophage (anti-CD68) staining. Pictures are representative of 3 experiments. ( $G$ and H) Livers were used to measure triglyceride $(\mathbf{G})$ and TBARS $(\mathbf{H})$. Mean \pm SD; ${ }^{* * * *} P<0.0001$, Welch's 2-tailed $t$ test. (I) Plasma ALT and $\beta$-HB levels in $\mathrm{Cl}^{419 / / 19}$ mice injected with $\mathrm{CoCl}_{2}$. Mean $\pm \mathrm{SD}$; ${ }^{* *} P<0.01,{ }^{* * * *} P<0.0001$, Welch's 2-tailed $t$ test. (J) $C I k^{d 19 / 119}$ and $C l k^{\text {wt/wt }}$ mice were injected with $\mathrm{CoCl}_{2}$. Two weeks later, mice were injected i.p. with $\left[{ }^{3} \mathrm{H}\right] \mathrm{OA}$. After 2 hours, livers were collected, and radioactivity was measured. Mean $\pm \mathrm{SD} ;{ }^{* * *} P<$ 0.0001, Welch's 2-tailed $t$ test. (K) Liver slices from 10-month-old CI $\mathrm{k}^{\Delta 19 / 119}$ and $\mathrm{Cl}^{\mathrm{wt} / \mathrm{wt}}$ mice treated with $\mathrm{CoCl}$, were incubated with $\left[{ }^{3} \mathrm{H}\right] \mathrm{OA}(1 \mu \mathrm{Ci} / \mathrm{mL})$ for 1 hour, washed, and used to measure protein and radioactivity. Mean $\pm S D$; ${ }^{*} P<0.05,{ }^{* * *} P<0.0001,2$-way ANOVA, Šidák's multiplecomparisons test. (L) Liver slices from 10-month-old $C \mathbb{k}^{119 / 419}$ and $C \mathrm{~K}^{\mathrm{wt} / \mathrm{wt}}$ mice treated with or without $\mathrm{CoCl}_{2}$ were incubated with $\left[{ }^{14} \mathrm{C}\right]$ palmitic acid (PA) $(1 \mu \mathrm{Ci} / \mathrm{mL})$ for 2 hours. ${ }^{14} \mathrm{CO}_{2}$ adsorbed to paper and acid-precipitated intermediates were counted. Mean $\pm \mathrm{SD}$; ${ }^{*} P<0.05$, ${ }^{*} P<0.01$, 2-way ANOVA, Šidák's multiple-comparisons test. (M) Primary hepatocytes from $\mathrm{Cl}^{419 / 419}$ and $\mathrm{Cl} \mathrm{k}^{\mathrm{wt} / \mathrm{wt}}$ mice were treated with $\mathrm{CoCl}_{2}(250 \mu \mathrm{M})$ for 12 hours, incubated with $0.5 \mu \mathrm{Ci} / \mathrm{mL}$ of $\left[{ }^{3} \mathrm{H}\right] \mathrm{OA}$ for 1 hour, washed, and counted. Mean $\pm \mathrm{SD} ;{ }^{*} P<0.05,{ }^{* *} P<0.01,{ }^{* * *} P<0.0001,2$-way ANOVA, Šidák's multiple-comparisons test. (N) Primary hepatocytes from CI/ $\mathrm{K}^{419 / 419}$ and Clk $k^{\text {wt/wt }}$ mice were treated with DMOC $(500 \mu \mathrm{M})$ for 8 hours, incubated for 1 hour with $0.5 \mu \mathrm{Ci} / \mathrm{mL}\left[{ }^{3} \mathrm{H}\right] \mathrm{OA}$, and washed, and radioactivity was determined to measure uptake or hepatocytes were incubated with $\left[{ }^{14} \mathrm{C}\right] \mathrm{PA}$ for 1 hour to study fatty acid oxidation. Mean $\pm \mathrm{SD} ;{ }^{*} P<0.05$, ${ }^{* * *} P<0.001$, 2-way ANOVA, Šidák's multiple-comparisons test. (0) WT hepatocytes were transduced in triplicate with adenoviruses expressing shCLOCK, shHIF1 $\alpha$, shCD36, or shCTRL. After 60 hours, cells were treated with $\mathrm{CoCl}_{2}$ for 12 hours and fatty acid uptake was measured. Mean $\pm S D$; ${ }^{* *} P<0.001$, 2-way ANOVA, Šidák's multiple-comparisons test.

cine (DMOG), another activator of HIF1 $\alpha$ (26). Similar studies in Huh7 cells transfected with siClk and treated with $\mathrm{CoCl}_{2}$ or DMOG showed increased fatty acid uptake but reduced fatty acid oxidation in Huh7 cells (Supplemental Figure 7). Thus, activation of HIF1 $\alpha$ increases uptake of fatty acids but decreases their oxidation in CLOCK-deficient cells compared with control cells.

To assess whether increased uptake of fatty acids by the liver was due to upregulation of HIF1 $\alpha$ and CD36, isolated primary hepatocytes were transduced with adenoviruses expressing short hairpin (sh) shClk, shHifla, or shCd36 and were treated with $\mathrm{CoCl}_{2}$ (Figure 2O). $\mathrm{CoCl}_{2}$ treatment increased fatty acid uptake in control and shClk-treated hepatocytes. However, cells exposed to shHifla, shCd36, and both shHifla and shCd36 did not show increased fatty acid uptake after $\mathrm{CoCl}_{2}$ treatment. These studies suggested that HIF1 $\alpha$ and CD36 participate in increased fatty acid uptake induced by $\mathrm{CoCl}_{2}$.

The above studies identified HIF1 $\alpha$ as a transcription factor involved in the upregulation of CD36 and in the induction of hepatosteatosis in $C l k^{419 / 419}$ mice. We hypothesized that knockdown of HIF1 $\alpha$ may prevent development of steatosis and hepatosteatosis in $C l k^{419 / 419}$ mice. Injection of shHifla in chow-fed $\mathrm{Clk}^{419 / \Delta 19}$ mice significantly reduced expression of Hifl $\alpha$ and levels of its target $\operatorname{Veg} f$ (Figure $3 \mathrm{~A}$ ) and reduced $C d 36$ mRNA (Figure $3 \mathrm{~A}$ ) and protein (Figure 3A, inset) levels. Livers of $C l k^{419 / 419}$ mice transduced with
shHifla took up less fatty acid (Figure 3B). These mice had lower levels of hepatic TBARS, triglyceride, and cholesterol (Figure 3C), lower levels of plasma ALT and triglyceride, and normal levels of plasma cholesterol and $\beta$-HB (Figure 3D). Histologic studies showed reduced lipid staining, hepatocyte ballooning, macrophage infiltration, and HIF1 $\alpha$ protein expression in shHifl $\alpha$-recipient mice (Figure 3E). Transmission electron microscopy showed fewer lipid droplets in the livers of shHiflo-recipient Clk $^{119 / \Delta 19}$ mice (Figure 3F). Expression analyses revealed reduced mRNA levels of lipogenesis and inflammatory response genes (Figure 3G). shHifl $\alpha$ had no effect on ER stress or cancer gene expression. These studies indicated that reduced HIF1 $\alpha$ expression decreases the expression of genes in steatosis and inflammation and may help ameliorate steatohepatitis.

Hepatosteatosis and cirrhosis in Clk ${ }^{119 / 419}$ mice challenged with lipopolysaccharide. Next, we asked how Western diet-fed Clk $k^{119 / 419}$ male (Figure 4) and female (Supplemental Figure 8) mice would respond to a lipopolysaccharide (LPS) challenge that is known to induce an inflammatory response. LPS-injected $C l k^{119 / 419}$ mice developed hepatomegaly and micronodular cirrhosis (Figure 4A). Livers from these mice showed increased Oil Red O (Figure 4B and Supplemental Figure 8A) and anti-macrophage staining (Figure 4B) compared with $C l k^{w t / w t}$ mice. $C l k^{419 / 419}$ livers had significantly higher amounts of triglyceride, cholesterol (Figure $4 \mathrm{C}$ and Supplemental Figure 8B), and TBARS (Figure 4D and Supplemental Figure $8 \mathrm{C}$ ). These mice contained significantly more ALT but reduced levels of $\beta$-HB (Figure 4E and Supplemental Figure 8D). $C l k^{419 / 419}$ livers took up more i.p.-injected OA (Figure 5A and Supplemental Figure 8E). Fatty acid oxidation was reduced (Figure 5B and Supplemental Figure 8E). Livers of $\mathrm{Clk}^{419 / 419}$ mice showed increased expression of the inflammatory response (Figure $5 \mathrm{C}$ and Supplemental Figure 8F) and ER stress genes (Figure 5D and Supplemental Figure 8G). There were modest increases in $M d m 2$ and $C-m y c$ and reductions in Trp53, indicating changes favoring cancer in $C l k^{119 / 419}$ mice (Figure $5 \mathrm{E}$ and Supplemental Figure $8 \mathrm{H}$ ). Expression analyses also revealed induction of genes involved in lipogenesis and lipoprotein assembly as well as suppression of fatty acid oxidation (Figure 5F and Supplemental Figure 8I). Further, there were significant reductions in Egln2, Egln1, and Egln 3 mRNA levels (Figure 5G and Supplemental Figure 8J). Thus, LPS increases steatosis, ER stress, and inflammatory response in $\mathrm{Clk}^{119 / 419}$ mice, suggesting that these factors may promote cirrhosis.

LPS-treated $C l k^{119 / 419}$ mice had significantly lower levels of hepatic Egln2, Egln1, and Egln3 mRNA levels (Figure 5G). There was no change in Hifl $\alpha$ mRNA levels compared with controls. We also studied the effects of CLOCK knockdown and LPS treatment in human hepatoma Huh7 cells (Figure $5 \mathrm{H}$ ). siClk reduced the mRNA level of EGLN2, EGLN1, and EGLN3 and HIF1 $\beta$ but had no effect on HIF1 $\alpha$ and GAPDH (Figure $5 \mathrm{H}$ ), and this response was considerably enhanced after LPS treatment. Next, we looked at changes in protein levels. HIF1 $\alpha$ and CD36 protein levels increased in LPS-treated $C l k^{419 / 419}$ mice compared with controls (Supplemental Figure 8K). siClk increased CD36 and HIF1 $\alpha$ protein levels in Huh7 cells, and these protein levels increased more after LPS treatment (Figure 5I). siClk reduced PHD1 and PHD2 protein levels; LPS further reduced these protein levels (Figure 5I). Further, the binding of HIF1 $\alpha$ to the $C d 36$ promoter was high 
A

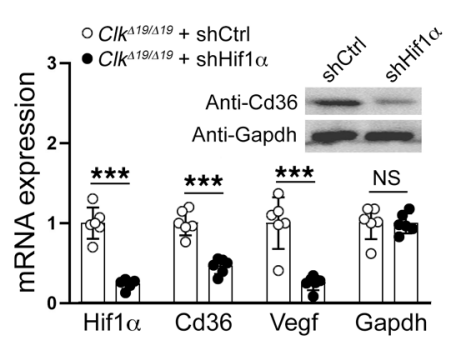

B Injected i.p.
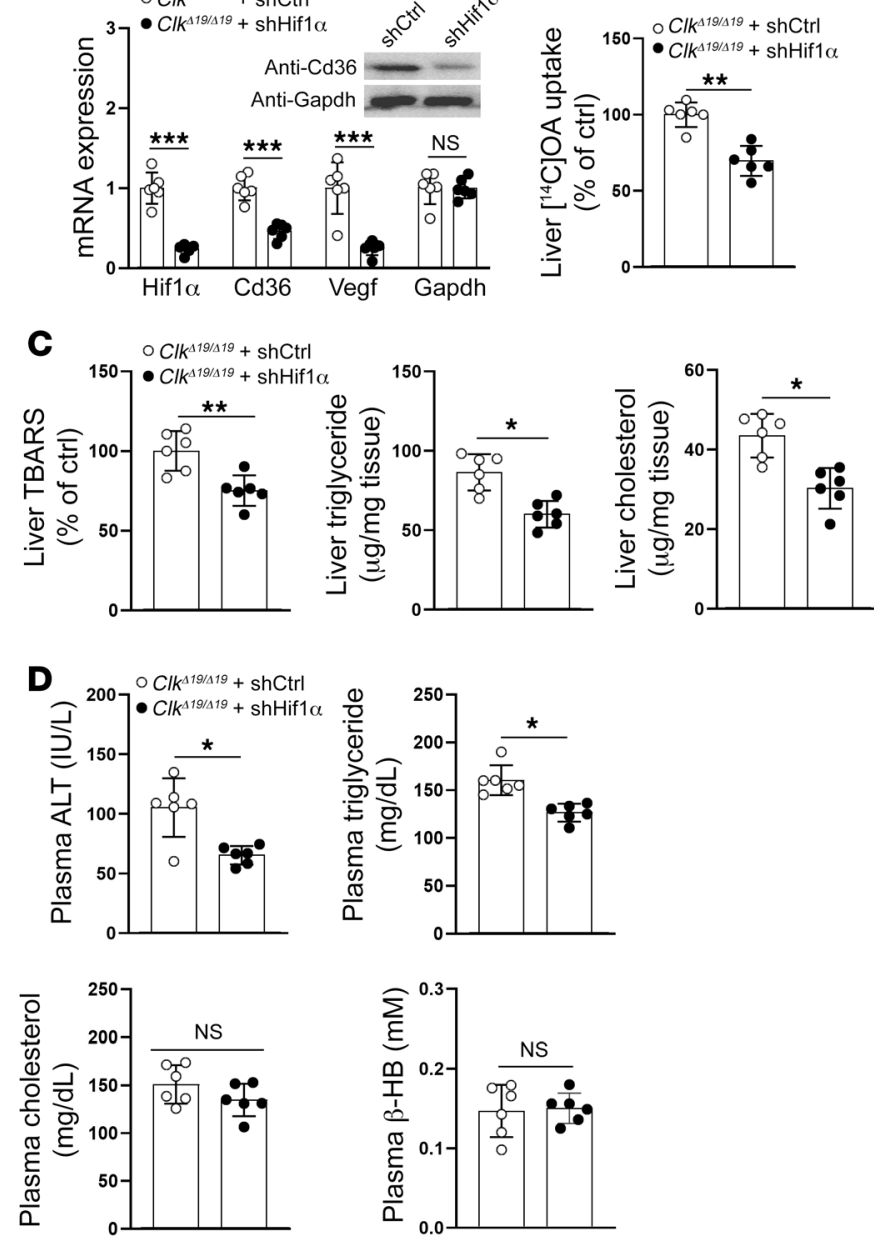

E
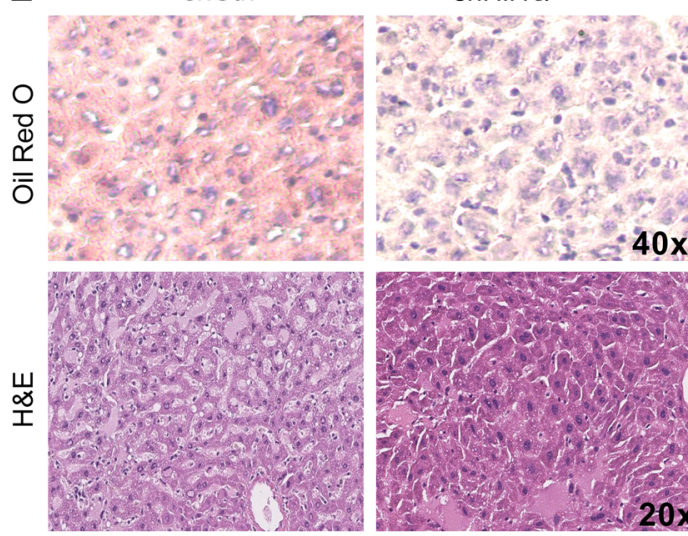

$\sum_{\substack{1 \\ \hline}}^{0}$

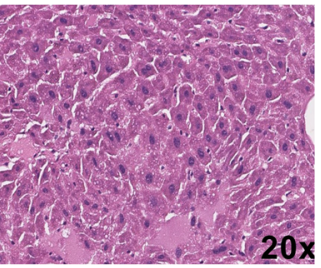

$20 x$

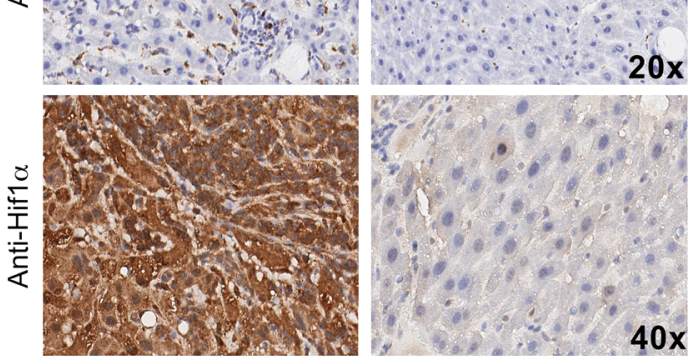

F
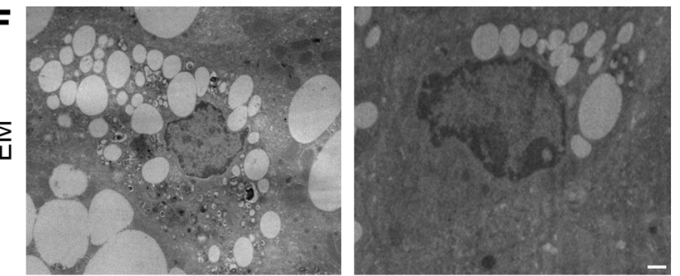

G
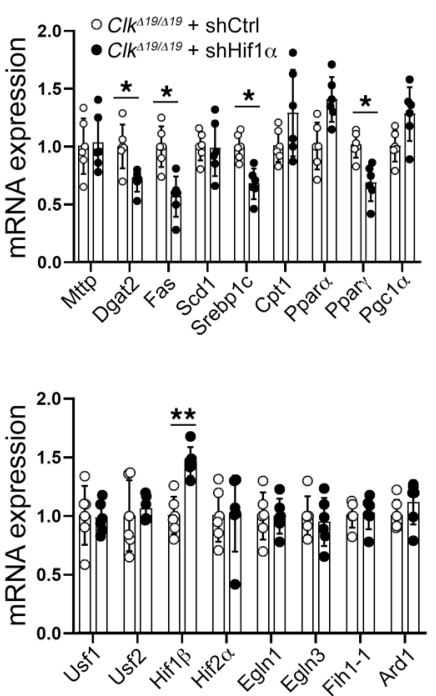
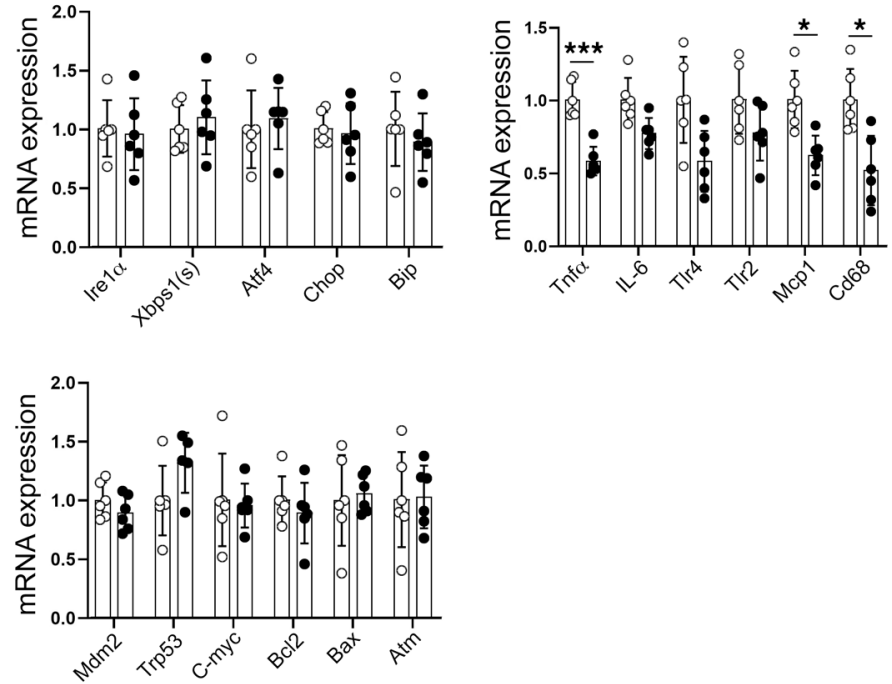
Figure 3. Decreased hepatosteatosis after knockdown of HIF1 $\alpha$ in $\mathrm{Clk}^{419 / 419}$ mice. $C l k^{119 / 419}$ mice (male, 10 months old, chow-fed, 5-6 per group) were injected once via tail vein with lentiviruses expressing either shCtrl or shHIF1 $\alpha\left(1 \times 10^{9} \mathrm{PFU} /\right.$ mouse $)$. After 2 weeks, plasma and livers were collected. Another set of animals was used for fatty acid uptake studies $(n=3$ per group). (A) Liver samples were used to measure Hif1 $\alpha$, Cd36, Vegf, and Gapdh mRNA and protein levels of CD36 and Gapdh (inset). Mean \pm SD; ${ }^{* * *} P<0.001$, multiple $t$ tests. (B) For hepatic fatty acid uptake, mice were injected i.p. with $1.0 \mu \mathrm{Ci} /$ mouse of $\left[{ }^{3} \mathrm{H}\right] \mathrm{OA}$. After 2 hours, livers were collected to measure radioactivity. Mean $\pm \mathrm{SD}$; ${ }^{* *} P<0.0001$, Welch's 2-tailed $t$ test. (C) Liver triglyceride, cholesterol, and TBARS levels were lower in

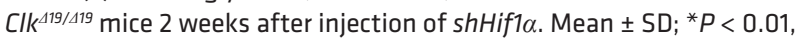
${ }^{* *} P<0.001$, Welch's 2-tailed $t$ test. (D) Plasma ALT and triglyceride levels were reduced in shHif1 $\alpha$-injected $C / k^{191 / 119}$ mice, but plasma cholesterol and $\beta-\mathrm{HB}$ concentrations were normal. Mean $\pm \mathrm{SD}$; ${ }^{*} P<0.001$, Welch's 2 -tailed $t$ test. (E) Liver sections were stained with Oil Red $\mathrm{O}, \mathrm{H} \& \mathrm{E}$, and anti-macrophage and anti-HIF1 $\alpha$ antibodies. Data are representative of 2 experiments. (F) Transmission electron microscopy (EM) revealed reduced lipid droplets in Clk ${ }^{\Delta 19 / \Delta 19}$ mice injected with shHif1 $($ scale bar: $100 \mu \mathrm{m}$ ). (G) Quantification of different mRNAs in livers of $C \mathrm{~K}^{119 / 419}$ mice 2 weeks after injection of shHIF1 $\alpha$. Mean $\pm \mathrm{SD}$; ${ }^{*} P<0.05,{ }^{* *} P<0.01,{ }^{* *} P<0.001$, multiple $t$ tests.

in $C l k^{119 / 119}$ mice. This binding increased in LPS-injected mice (Figure 5J). These studies indicated that an inflammatory insult augments HIF1 $\alpha$ and CD36 proteins in $\mathrm{Clk}^{119 / 419}$ mice. Thus, normal CLOCK activity may reduce an LPS-induced inflammatory response in $C l k^{w t / w t}$ mice.

$\mathrm{Clk}^{119 / 119} \mathrm{Apoe}^{-/-}$mice develop steatohepatitis and cirrhosis with age on chow diet. We showed that $\mathrm{Clk}^{119 / 419} \mathrm{Apoe}^{-/-}$mice develop more robust atherosclerosis than Apoe - $^{-/}$mice (15). Here, we studied changes in the livers of $\mathrm{Clk}^{119 / 119} \mathrm{Apoe}^{-/-}$mice fed a chow diet and compared them with livers of control Apoe $e^{-/}$mice. Apoe ${ }^{-1-}$ mice do not develop liver diseases on chow diet; however, they do develop steatosis, NASH, and fibrosis when fed different diets (27, 28). To avoid the effects of Western diet, $C l k^{119 / 119} \mathrm{Apoe}^{-/}$mice were fed only a chow diet, and development of NAFLD was compared against $\mathrm{Apoe}^{-/-}$mice. Hepatic triglyceride levels were higher at 3 and 6 months but lower at 12 months in $\mathrm{Clk}^{119 / 419} \mathrm{Apoe}^{-/-}$mice compared with controls (Figure 6A). Hepatic levels of TBARS, cholesterol (not shown), and free fatty acids increased with age in these mice (Figure 6A). Plasma ALT levels were significantly higher only in older mice, but $\beta$-HB levels were significantly reduced (Figure 6B). $\mathrm{Clk}^{419 / 419} \mathrm{Apoe}^{-/-}$livers assimilated more fatty acids from plasma than did control livers in mice of all ages (Figure 6C). More lipid accumulation as droplets was evident in 2- and 10-monthold $\mathrm{Clk}^{119 / 119} \mathrm{Apoe}^{-/-}$livers after Oil Red O staining (Figure 6D). $\mathrm{H} \& \mathrm{E}$ staining showed increased ballooning with age (Figure 6E). Electron microscopy showed accumulation of larger lipid droplets in 10-month-old $\mathrm{Clk}^{119 / 19} \mathrm{Apoe}^{-/-}$mice (Figure 6F). $\mathrm{Clk}^{119 / 19}$ Apoe $^{-/-}$livers showed more macrophage staining (Figure 6G) and had more TUNEL-positive cells (Figure 6H) than controls. Binding of HIF1 $\alpha$ to the $C d 36$ promoter was higher in $C^{1 k 19 / 419}$ $\mathrm{Apoe}^{-/-}$mice than in controls (Figure 6I). Livers of 12-month-old $\mathrm{Clk}^{119 / 119} \mathrm{Apoe}^{-/-}$mice were larger and showed micronodular cirrhosis (Figure 6J). These studies indicated that chow-fed $\mathrm{Clk}^{119 / 419}$ $\mathrm{Apoe}^{-/-}$mice develop steatohepatitis and cirrhosis with age.

We then concentrated on understanding factors contributing to cirrhosis. Three-month-old $\mathrm{Clk}^{119 / 119} \mathrm{Apoe}^{-/-}$mice had higher plasma triglycerides, whereas 12-month-old mice had lower plasma triglyceride levels, than Apoe ${ }^{-/}$mice (Figure 7A). Triglyceride production studies in lipase-inhibited mice showed that $\operatorname{Clk}^{119 / 19}$ $\mathrm{Apoe}^{-/-}$mice produced more triglyceride-containing lipoproteins at 3 months but produced less of these lipoproteins at 1 year compared with Apoe ${ }^{-/-}$mice (Figure 7B). Activity and mRNA levels of Mttp were higher in young $\mathrm{Clk}^{119 / 419} \mathrm{Apoe}^{-/-}$animals but lower in older mice (Figure 7C). These studies showed that young $\mathrm{Clk}^{119 / 119}$ $\mathrm{Apoe}^{-/-}$mice produce more hepatic lipoproteins, probably because of increased Mttp and Dgat 2 expression. With increasing age, lipoprotein production and Mttp expression decrease in these mice.

Younger $\mathrm{Clk}^{119 / 419} \mathrm{Apoe}^{-/-}$mice showed no difference in fatty acid $\beta$-oxidation compared with $A p o e^{-/-}$mice; however, 12-monthold $\mathrm{Clk}^{19 / 419} \mathrm{Apoe}^{-/-}$mice showed reduced $\beta$-oxidation as well as reduced expression of Ppara, Pgc1, Pgc1 $\beta$, and Cpt1 (Figure 7D). Livers of older $\mathrm{Clk}^{119 / 119} \mathrm{Apoe}^{-/-}$mice assimilated significantly higher amounts of i.p.-injected OA (Figure 7E). Protein and mRNA levels of CD36 were significantly (approximately 5-fold) higher in older mice (Figure 7F). These studies show that livers of older $\mathrm{Clk}^{119 / 119} \mathrm{Apoe}^{-/-}$mice take up more fatty acids but produce fewer lipoproteins and store less triglyceride.

There were significant reductions of Egln2, Egln1, and $E g \ln 3$ mRNA levels but no effect on Hifl $\alpha$ and Hifl $\beta$ mRNA levels (Figure 7G). Nonetheless, protein levels of HIF1 $\alpha$ increased in $\mathrm{Clk}^{191 / 19}$ Apoe $^{-/}$mice (Figure 7F). In the ER stress pathway, only Ire1 $\alpha$ levels were significantly increased (Figure 7H). Further, there were modest changes in the proto-oncogenes and tumor suppressor genes, indicating a carcinogenic response. In contrast to these modest changes, we observed that mRNA levels of Tnf $\alpha$ and Il6 increased 5- to 10-fold in older $\mathrm{Clk}^{119 / 119} \mathrm{Apoe}^{-/-}$mice compared with $A p o e^{-/-}$mice, indicating significant upregulation of the inflammatory response. In short, $\mathrm{Clk}^{119 / 19} \mathrm{Apoe}^{-/-}$mice showed reduced expression of genes in lipoprotein production and $\beta$-oxidation but increased expression of inflammatory response genes with age compared with $A p o e^{-/-}$mice. These changes may represent, or cause, a transition from NASH to cirrhosis.

LPS induces macronodular cirrhosis in $\mathrm{Clk}^{119 / 419} \mathrm{Apoe}^{-/-}$mice. $\mathrm{Clk}^{119 / 119} \mathrm{Apoe}^{-/,}$, but not Apoe-/, mice injected with LPS developed macronodular cirrhosis (Figure 8A). LPS-injected Clk $191 / 19$ $\mathrm{Apoe}^{-/-}$mice had lower hepatic triglyceride (Figure 6B), higher TBARS (Figure 8B), higher plasma ALT levels, and lower $\beta$-HB (Figure 8C) than Apoe ${ }^{-/-}$mice. $\mathrm{Clk}^{119 / 19} \mathrm{Apoe}^{-/-}$livers took up fewer fatty acids (Figure 8D) but more 3-3'-dioctadecylindocarbocyanine-labeled (DiI-labeled) acetylated LDL (AcLDL) (Figure $8 \mathrm{E}$ ). They showed less $\beta$-oxidation (Figure $8 \mathrm{~F}$ ). Histologic analyses showed less lipid accumulation but more macrophages and some hyperplasia (Figure 8G). Gene expression analysis showed reduced expression of Egln2, Egln1, and $E g \ln 3$ and high expression of Cd36 (Supplemental Figure 9A). Expression of genes involved in lipoprotein assembly and fatty acid oxidation decreased, whereas expression of those involved in lipogenesis increased (Supplemental Figure 9B). There were significant increases in inflammatory markers (Supplemental Figure 9C) and cancer markers (Supplemental Figure 9D) with modest effect on ER stress genes (Supplemental Figure 9E). These studies indicate that, compared with $\mathrm{Apoe}^{-/-}$mice, $\mathrm{Clk}^{419 / 419} \mathrm{Apoe}^{-/-}$ mice express higher amounts of genes involved in inflammation 

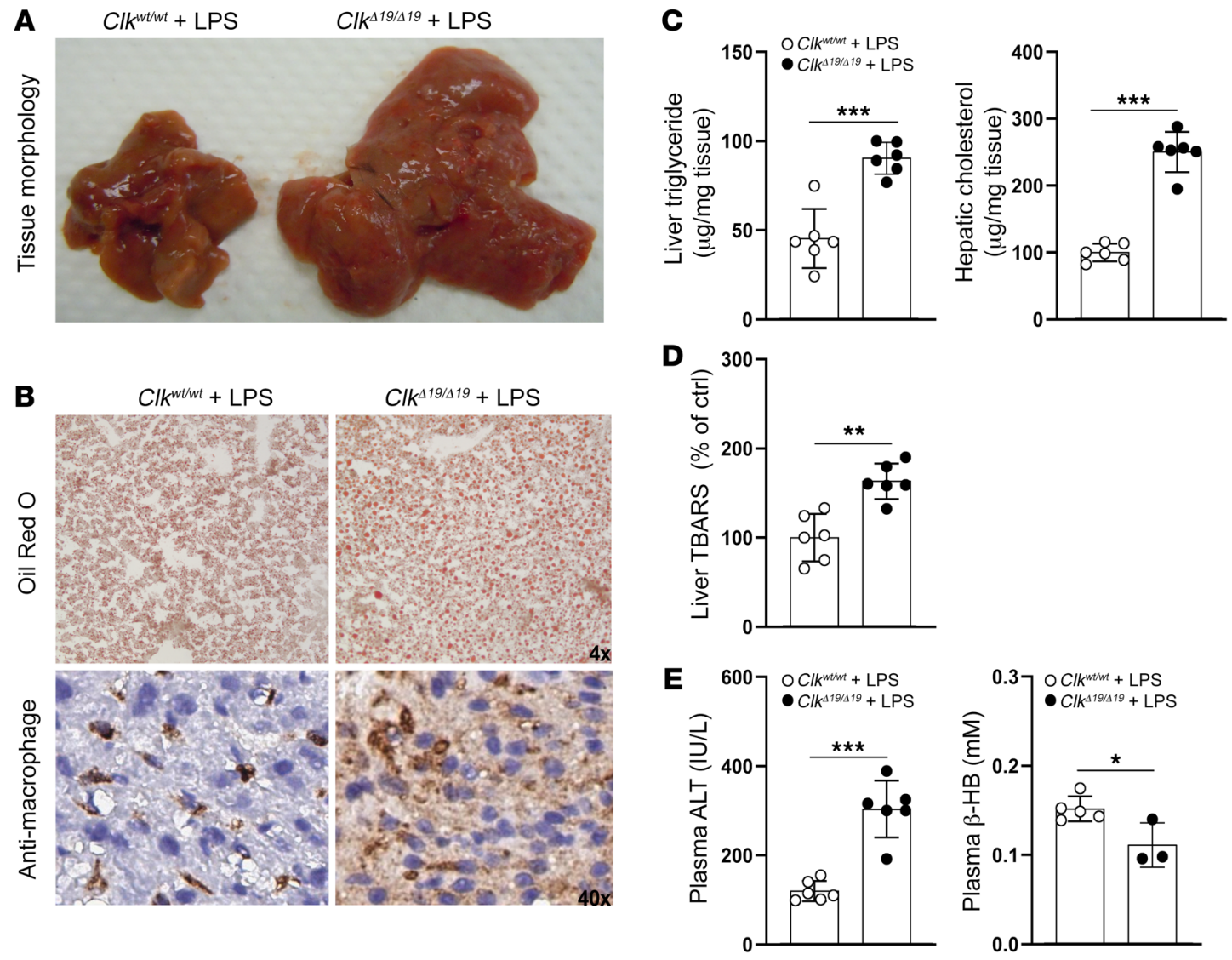

Figure 4. LPS-induced hepatosteatosis and cirrhosis in $\mathbf{C l k}^{419 / \Delta 19}$ mice. Male (8-month-old) $C l k^{419 / \Delta 19}$ and $C l k^{\text {wt } / w t}$ mice on a chow diet were fed a Western diet for 2 months and injected i.p. with LPS ( $0.25 \mathrm{mg} / \mathrm{kg}$ per injection, 3 times on alternate days). Mice then continued on a Western diet for an additional 2 months, and livers and plasma were collected for analyses at the end ( $n=6$ per group). (A) Livers from LPS-injected Clk ${ }^{419 / 419}$ mice showed hepatomegaly and micronodular cirrhosis. Pictures are representative of 2 experiments. (B) Frozen liver sections were stained with Oil Red O, H\&E, and anti-macrophage antibodies. Representative of 2 experiments. (C and D) Liver pieces were used to measure triglyceride, cholesterol (C), and TBARS (D) levels. Mean \pm SD; ${ }^{* *} P<0.01,{ }^{* *} P<0.0001$, Welch's 2 -tailed $t$ test. (E) Plasma ALT and $\beta$-HB levels were measured in LPS-injected $C I / k^{419 / 419}$ mice. Mean $\pm \mathrm{SD} ;{ }^{*} P<0.05$, ${ }^{* * *} P<0.0001$, Welch's 2-tailed $t$ test.

and cancer when challenged with LPS, suggesting a transition from cirrhosis to carcinogenesis.

$\mathrm{CoCl}_{2}$ induces HCC in $\mathrm{Clk}^{119 / 419} \mathrm{Apoe}^{-/-}$mice. To explore the effects of HIF1 $\alpha$ activation in $\mathrm{Clk}^{119 / 119} \mathrm{Apoe}^{-/-}$mice, we injected mice with $\mathrm{CoCl}_{2}$ and compared them with $\mathrm{CoCl}_{2}$-injected $\mathrm{Apoe}^{-/-}$mice. Livers of $\mathrm{CoCl}_{2}$-injected $\mathrm{Clk}^{119 / 419} \mathrm{Apoe}^{-/}$mice had solid tumors (Figure 9A). $\mathrm{CoCl}_{2}$ had no effect on hepatic Hifla and Hifl $\beta$ mRNA levels but significantly reduced levels of Egln1 and Egln 3 mRNA (Figure 9B) and increased Vegf mRNA in Clk ${ }^{119 / 419}$ Apoe $^{-/}$compared with Apoe ${ }^{-/}$mice. In addition, Cd36 mRNA levels increased significantly in $\mathrm{Clk}^{119 / 119} \mathrm{Apoe}^{-/-}$mice compared with $\mathrm{Apoe}^{-/-}$mice (Figure 9B). Western blotting showed significant increases in HIF1 $\alpha$ and CD36, decreases in PHD proteins, but no change in HIF1 $\beta$ and $\beta$-actin protein levels (Figure 9C). Immunohistochemistry showed increased HIF $1 \alpha$ and CD36 protein levels and macrophage staining (Figure 9D). Expression levels of ER response genes Ire1 $\alpha, X b p 1$, and Bip were higher (Figure $9 \mathrm{E})$. In addition, there was significant induction of CCAAT/ enhancer-binding protein homologous protein (CHOP). Tnfo, Il6, and Tlr4 mRNA levels increased more than 10-fold, indicating a significant inflammatory response. Levels of the proto-oncogenes
$M d m 2, C-m y c$, and $B c l 2$ increased significantly, whereas the level of the tumor suppressor gene Trp53 decreased significantly, which suggests carcinogenesis. Indeed, staining showed hyperplasia and no lipid deposition (Figure 9F). These studies suggest that $\mathrm{CoCl}_{2}$ treatment increases expression of HIF1 $\alpha$ in $\mathrm{Clk}^{119 / 419}$ $\mathrm{Apoe}^{-/-}$mice compared with $\mathrm{Apoe}^{-/-}$mice and induces an inflammatory response and expression of genes that favor carcinogenesis. Thus, pathologic upregulation of these genetic programs may be involved in the development of HCCs.

$\mathrm{CoCl}_{2}$ induces HIF1a in macrophages. We were surprised by the reduced lipid accumulation after Oil Red O staining in $\mathrm{CoCl}_{2}^{-}$ injected $\mathrm{Clk}^{119 / 119}$ mice compared with controls (Figure 9F). Consistent with reduced Oil Red O staining, triglyceride content was lower in $\mathrm{Clk}^{119 / / 19} \mathrm{Apoe}^{-/-}$mice (Figure 10A); however, liver TBARS (Figure 10B) and plasma ALT (Figure 10C) levels were significantly higher. In contrast, plasma $\beta$-HB levels were reduced (Figure 10C). To explore reasons for the reduced hepatic triglyceride levels, we studied fatty acid uptake. Despite significant increases in $C d 36$ mRNA and protein levels (Figure 9, B and C), the livers (Figure 10D) and isolated hepatocytes (Figure 10E) from $\mathrm{Clk}^{119 / 419} \mathrm{Apoe}^{-/-}$mice took up fewer fatty acids. To explain this discrepancy, we explored 

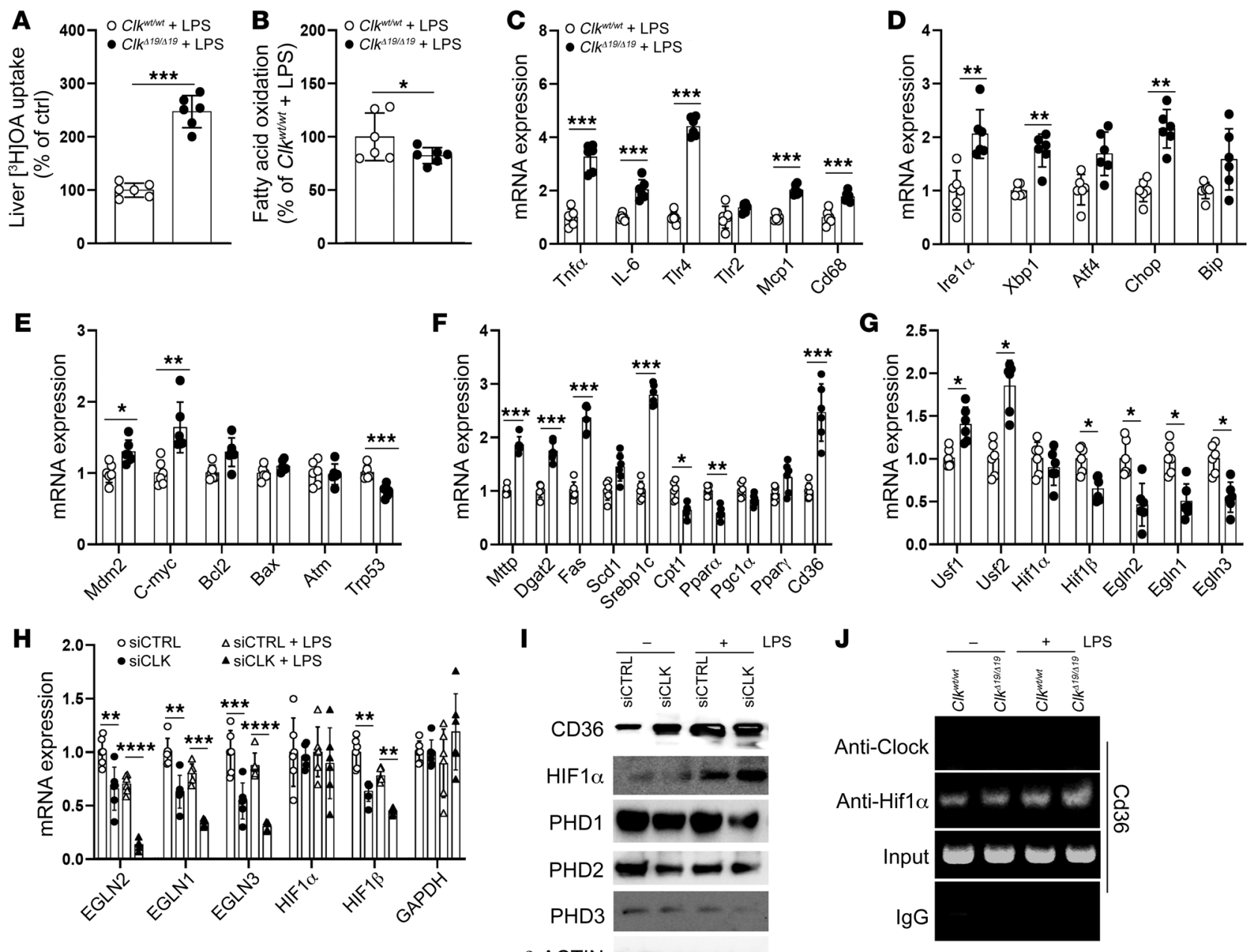

Figure 5. LPS induces HIF1 $\alpha$ and CD36 in Clk ${ }^{419 / 419}$ mice. Mice were treated with LPS as described in Figure 4 and used to study fatty acid uptake and oxidation ( $n=6$ per group). (A) Hepatic fatty acid uptake. LPS-injected $C I k^{419 / 419}$ mice took up more [ $\left.{ }^{3} \mathrm{H}\right] \mathrm{OA}$. Mean $\pm \mathrm{SD}$; ${ }^{* * *} P<0.001$, Welch's 2 -tailed $t$ test. (B) Fatty acid oxidation. Fresh liver slices from LPS-injected $\mathrm{Cl}^{\mathrm{d}}{ }^{119 / 419}$ mice were incubated with $\left[{ }^{14} \mathrm{C}\right] \mathrm{PA}(\mathrm{O} .2 \mu \mathrm{Ci})$ for 2 hours, and radiolabeled $\mathrm{CO}_{2}$ trapped on filter papers soaked with phenylethylamine was quantified. Mean \pm SD; ${ }^{*} P<0.05$, Welch's 2 -tailed $t$ test. (C-G) Quantification of different indicated mRNAs in livers of LPS-injected CI $k^{119 / 419}$ and $C I k^{\text {wt/wt }}$ mice. Mean $\pm \mathrm{SD} ;{ }^{*} P<0.05,{ }^{* *} P<0.01,{ }^{* * *} P<0.001$, multiple $t$ tests. (H and I) Human hepatoma Huh7 cells were transfected with siCTRL or siCLK. After 48 hours, they were treated or not with LPS $(25 \mathrm{ng} / \mathrm{mL})$ for 12 hours. RNA was isolated to quantify mRNA levels of indicated genes $(\mathbf{H})$ (mean $\pm \mathrm{SD}$; ${ }^{* *} P<0.01,{ }^{* *} P<0.001,{ }^{* * *} P<0.0001$, multiple $t$ tests; data representative of 2 experiments) and protein levels (I). (J) Livers from CI ${ }^{419 / 419}$ and CI $k^{\text {wt/wt }}$ mice injected or not with LPS were used to study the binding of CLOCK and HIF1 $\alpha$ by ChIP assay. Data are representative of 2 experiments.

several possibilities. First, we considered increased $\beta$-oxidation. However, we found reduced $\beta$-oxidation (Figure 10E) and lower expression of genes (Ppara and Cpt1) in this pathway (Figure 10F). Second, we considered the possibility that $\mathrm{Clk}^{119 / 419} \mathrm{Apoe}^{-/-}$mice produce more lipoproteins. However, we observed lower expression of genes involved in lipoprotein assembly and secretion (Mttp, Dgat2, and Scd1; Figure 10F). These studies showed that lipoprotein production were diminished. Therefore, reduced oxidation and lipoprotein production cannot explain lower hepatosteatosis.

Abnormally high mRNA levels of inflammatory response genes (Figure 9E) suggested a role for macrophages. Therefore, we hypothesized that $\mathrm{CoCl}_{2}$ may induce CD36 in hepatic Kupffer cells in $\mathrm{Clk}^{119 / 119} \mathrm{Apoe}^{-/-}$mice. Indeed, isolated Kupffer cells took up more oxidized LDL (oxLDL; Figure 10G). Further, we studied the effect of oxLDL and $\mathrm{CoCl}_{2}$ on Hifla and Cd36 expression in a J774 mouse macrophage cell line treated with siClk or siHifF1a (Supplemental Figure 10). siClk and siHifla significantly increased $C d 36$ but had no effect on $\beta$-actin mRNA and protein (Supplemental Figure 10, A-C) compared with siCtrl. OxLDL and $\mathrm{CoCl}_{2}$ further increased Cd36 mRNA and protein levels in siClk-treated cells (Supplemental Figure 10, A and C). OxLDL and $\mathrm{CoCl}_{2}$ increased HIF1 $\alpha$ protein levels, but not mRNA levels, in siClk-treated cells. Increases in HIF1 $\alpha$ protein levels were not seen in siHifl $\alpha$-treated cells (Supplemental Figure 10C). We also studied induction of HIF $1 \alpha$ and CD36 proteins in control and CLOCK-knockdown cells subjected to serum shock and exposed to oxLDL for various times (Supplemental Figure 10D). HIF1 $\alpha$ and CD36 proteins levels increased within 4 hours, and this response was transient in shCtrltreated cells, indicating temporal regulation. In shClk-treated cells, CD36 levels were induced faster, reached much higher lev- 

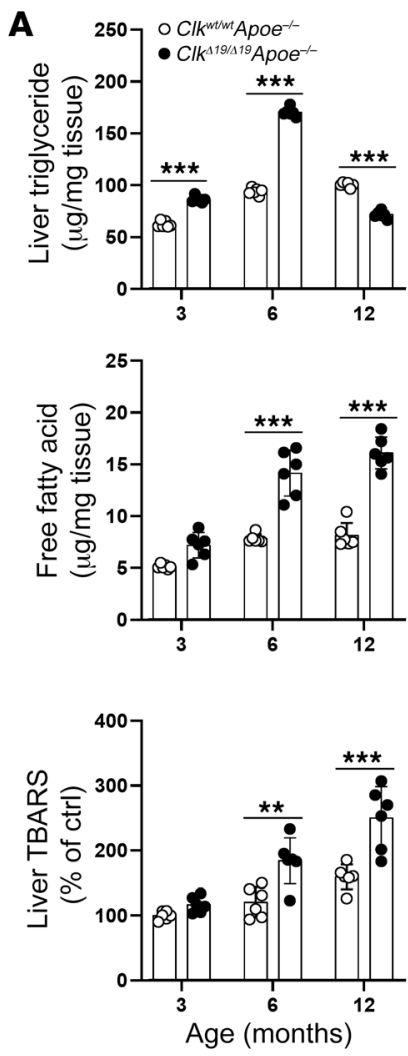

B
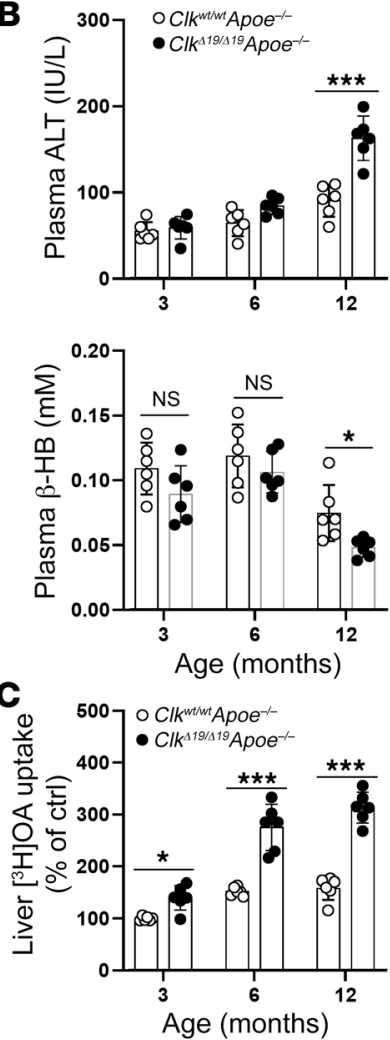

D

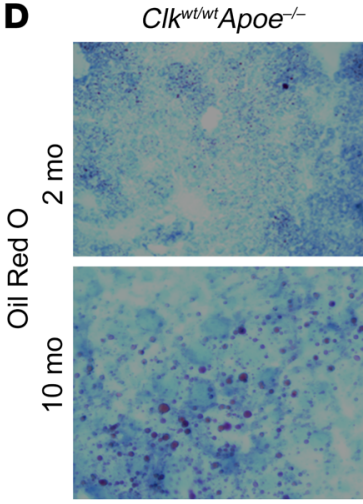

E

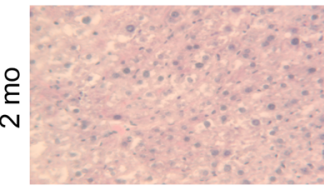

$\underset{\varpi}{\dddot{\varpi}}$
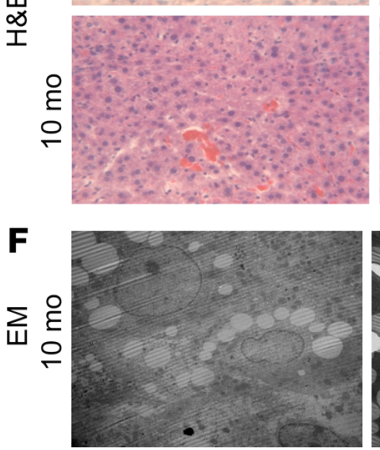

Clk ${ }^{\Delta 19 / \Delta 19} A$ poe ${ }^{-/-}$
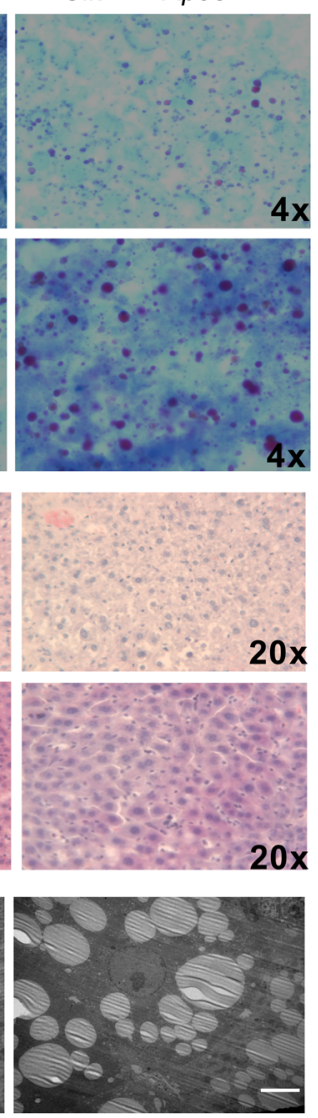

G

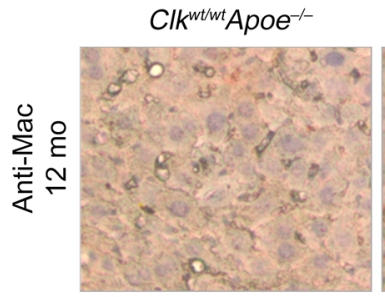

J

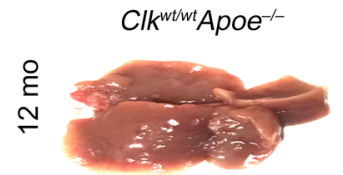

Clk ${ }^{\Delta 19 / \Delta 19}$ Apoe $^{-/-}$

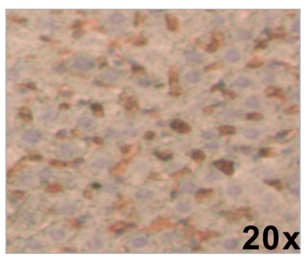

$\mathrm{Clk}^{119 / 419} \mathrm{Apoe}^{-/-}$

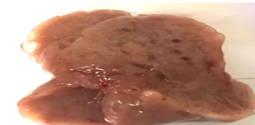

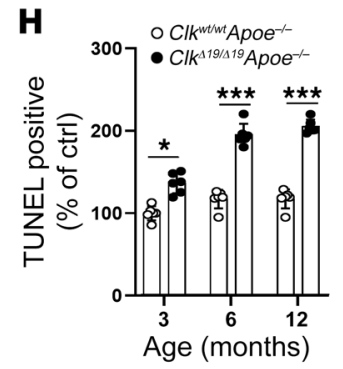

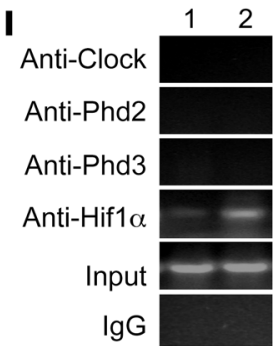

Figure 6. Age-dependent changes in hepatic lipid metabolism in $\mathbf{C l k}^{\Delta 19 / 419} \mathbf{A p o e}^{-/-}$mice. Male $\mathrm{Cl}^{\Delta 19 / 419} \mathrm{Apoe}^{-/-}$and $A p o e^{-/-}\left(\mathrm{Clk}^{\mathrm{wt} / \mathrm{wt}} \mathrm{Apoe^{-/- }}\right)$ mice were fed a chow diet, and livers and plasma were collected at 3 months ( $2-3$ months, $n=8$ per group), 6 months ( $5-6$ months, $n=6$ per group), or 12 months (10-12 months, $n=12$ per group). Mean $\pm \mathrm{SD}$; ${ }^{*} P<0.05$, ${ }^{* *} P<0.01,{ }^{* * *} P<0.001$, multiple $t$ tests. (A) Hepatic triglyceride, free fatty acid, and TBARS levels measured using kits. (B) Plasma ALT levels were high in older $\mathrm{Cl}^{119 / 419} \mathrm{Apoe}^{-/-}$mice. In contrast, plasma $\beta$-HB concentrations were low in older Clk ${ }^{419 / 419}$ Apoe $/$ mice. (C) $\left[{ }^{3} \mathrm{H}\right] \mathrm{OA}$ was injected i.p. into mice. Hepatic radioactivity was measured after 2 hours. (D and E) Liver sections were stained with Oil Red $\mathrm{O}$ (D) and H\&E (E) staining. Data are representative of 2 independent experiments. (F) Electron microscopy (scale bar: $100 \mu \mathrm{m}$ ) showed more lipid droplets in older $\mathrm{Clk}^{119 / 419} \mathrm{Apoe}^{-/-}$mice. Data are representative of 2 experiments. (C) Macrophage infiltration was determined by staining for CD68 in 12-month-old mice. Data are representative of 2 experiments. (H) Liver apoptotic cells were detected by TUNEL staining and were quantified. (I) Livers from mice (12 months old, chow diet) were used to study the binding of different proteins to the HIF1 $\alpha$ binding site in the Cd36 promoter. Data are representative of 2 experiments. (J) Representative photograph of livers in 12-month-old mice.

els, and remained high for longer times. Thus, CLOCK-deficient J774 cells respond to oxLDL and $\mathrm{CoCl}_{2}$ by augmenting HIF1 $\alpha$ and CD36 protein levels. Consistent with these studies, Kupffer cells isolated from $\mathrm{Clk}^{119 / 419} \mathrm{Apoe}^{-/-}$mice and treated with $\mathrm{CoCl}_{2}$ took up more DiI-AcLDL (Figure 10H) and expressed more $C d 36$ mRNA (Figure 10I). Further, the yield of Kupffer cells from $\mathrm{CoCl}_{2}$-treated $\mathrm{Clk}^{119 / 119} \mathrm{Apoe}^{-/-}$mice was 3-fold higher than that from $\mathrm{CoCl}_{2}$-treated $A p o e^{-/-}$mice. HIF1 $\alpha$ binding to the $C d 36$ promoter increased 

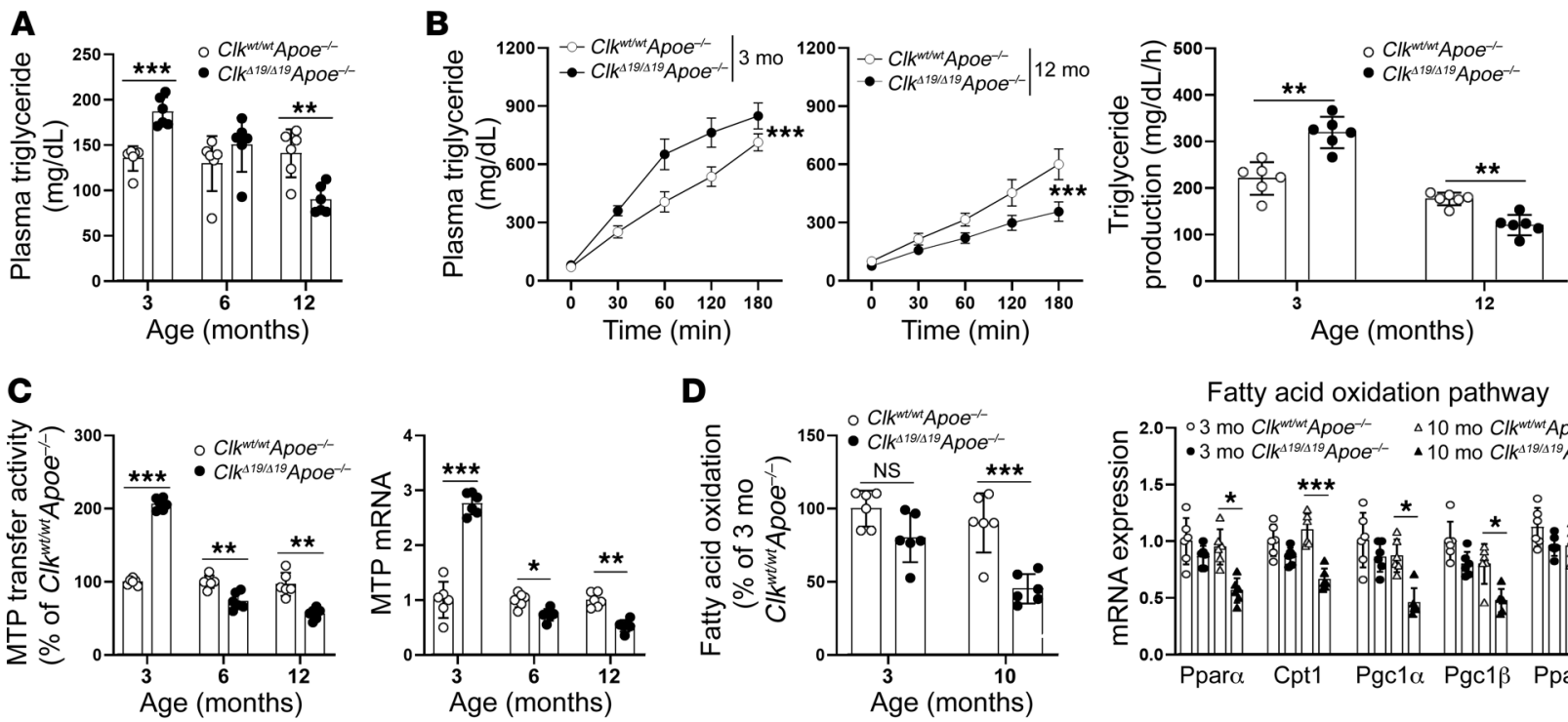

Fatty acid oxidation pathway
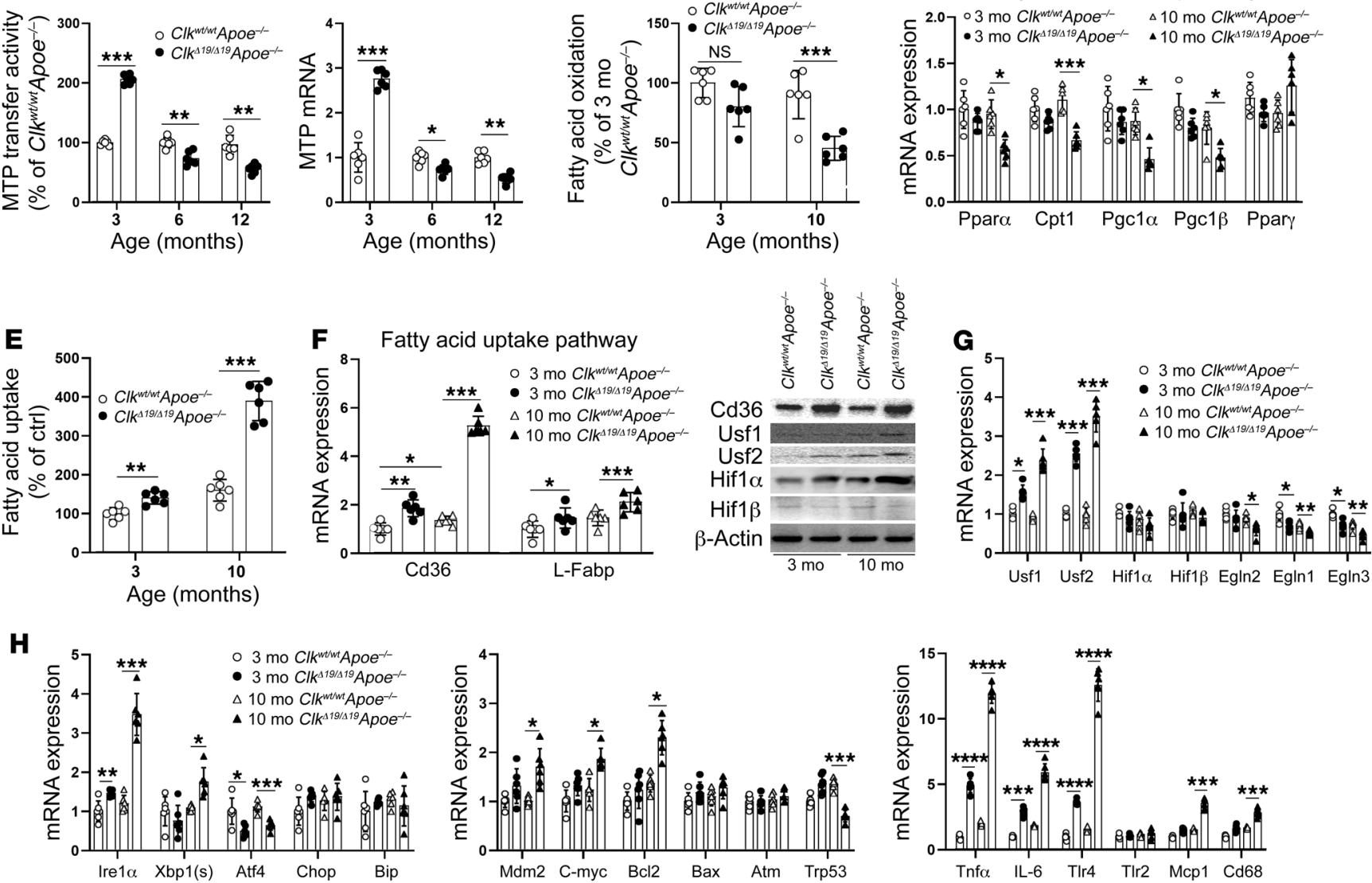

Figure 7. Factors contributing to cirrhosis in $\mathrm{Cl}^{\mathbf{4 1 9 / 4 1 9}} \mathbf{A p o e}^{-/-}$mice. Male mice ( $n=6$ per group) were fed a chow diet ad libitum, and livers and plasma were analyzed at indicated ages. (A) Plasma triglyceride levels were higher in younger mice but were lower in older $\mathrm{Clk}^{419 / 419} \mathrm{Apoe}^{-/-}$mice. (B) Overnight-fasted animals were injected with poloxamer 407 to inhibit lipases, and plasma triglyceride levels were determined at indicated times. Triglyceride production was higher in younger mice but was lower in older $\mathrm{Cl}^{191 / 419} \mathrm{Apoe}^{-/-}$mice. (C) Hepatic MTP activity (left) and mRNA levels (right) decreased with age in chow-fed male $\mathrm{Cl}^{419 / 419} \mathrm{Apoe}^{-/-}$mice. Similar changes in hepatic MTP protein levels were detected by Western blotting (data not shown). (D) Liver pieces in triplicate were incubated with [ $\left.{ }^{14} \mathrm{C}\right] \mathrm{PA}$ for 2 hours to measure fatty acid oxidation. Fatty acid oxidation (left) and expression of genes in fatty acid oxidation (right) were reduced in 12-month-old chow-fed male $\mathrm{Cl}^{419 / 419} \mathrm{Apoe}^{-/-}$mice. (E) Hepatic fatty acid uptake increased in older $\mathrm{Cl}^{419 / 419} \mathrm{Apoe} \mathrm{e}^{-/}$mice. (F) mRNA levels of genes in fatty acid uptake (Cd36 and L-Fabp) were quantified by quantitative real-time PCR (left). Indicated proteins were identified by Western blotting using specific antibodies (right). Data are representative of 2 experiments. (G) Egln mRNA levels were reduced in older $\mathrm{Cl}^{419 / 419} \mathrm{Apoe^{-/- }}$ mice. (H) Quantification of selected mRNAs in inflammatory response, ER stress, and carcinogenesis in livers of 12-month-old chow-fed male mice. Mean $\pm S D$; ${ }^{*} P<0.05$, ${ }^{* *} P<0.01,{ }^{* *} P<0.001,{ }^{* * *} P<0.0001,2$-way ANOVA, Šidák's multiple-comparisons test.

significantly in Kupffer cells isolated from $C l k^{419 / 419}$ and $C l k^{119 / 419}$ Apoe $^{-/-}$mice (Figure 10J). These studies suggest that CD36 is regulated similarly in hepatocytes and Kupffer cells in mice that express the CLOCK mutant protein. Thus, it is likely that, in the early stages of liver disease, CD36 expression increases in hepatocytes, leading to increased fatty acid uptake and steatosis. In advanced liver diseases, macrophages that express higher amounts of CD36 take up more modified lipoproteins.
Different pathways and molecules in the development of NAFLD in $C l k^{119 / 419}$ mice. Data from previous figures are summarized in Supplemental Figures 11 and 12 in an attempt to portray a comprehensive overview of various changes observed in $C l k^{419 / \Delta 19}$ and $\mathrm{Clk}^{119 / 419} \mathrm{Apoe}^{-/-}$mice with age and after various environmental insults. Young $C l k^{419 / 419}$ mice did not show steatosis (Supplemental Figure 11A). However, older mice developed steatosis on a chow diet, and this was accelerated when mice were fed a Western diet. 


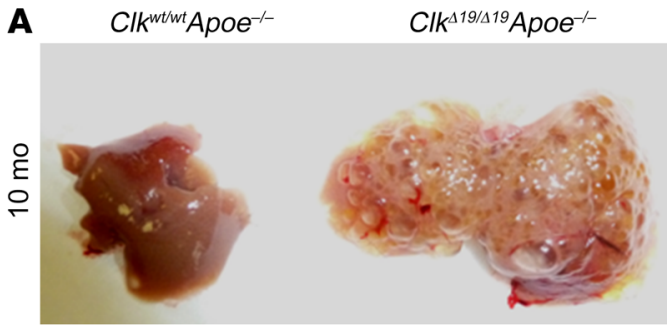

B
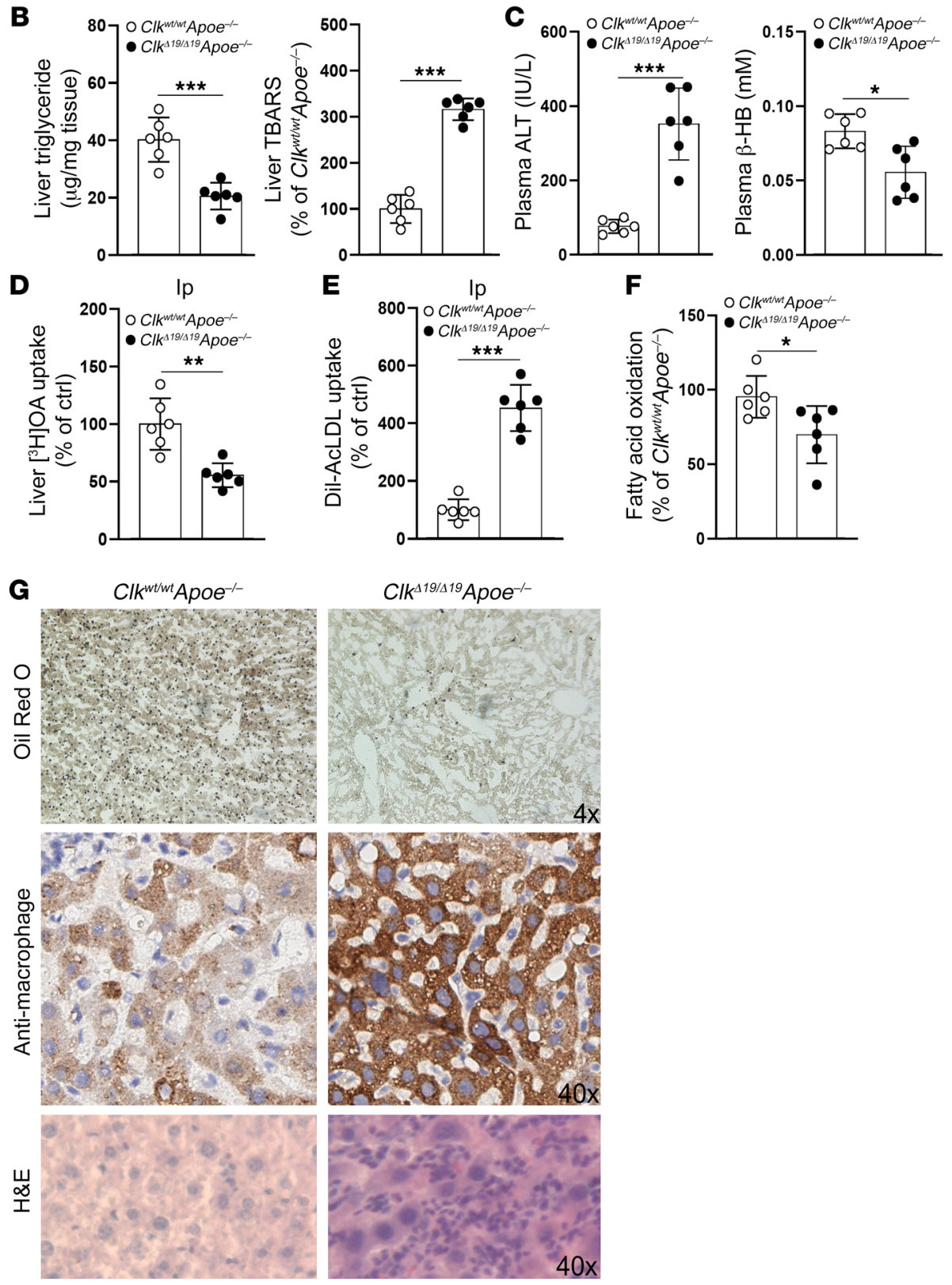

Exposure to LPS or $\mathrm{CoCl}_{2}$ induced cirrhosis. Thus, CLOCK deficiency increases the risk for steatosis, steatohepatitis, and cirrhosis. Although young $\mathrm{Apoe}^{-/-}$mice do not exhibit steatosis, young $\mathrm{Clk}^{119 / 119} \mathrm{Apoe}^{-/-}$mice exhibit both steatosis and NASH, and these mice develop cirrhosis with age on a chow diet. Thus, apoE deficiency is an additional risk factor for steatohepatitis and cirrhosis in $C_{l} k^{119 / 119}$ mice. It remains undetermined whether increased plasma lipoproteins and/or apoE deficiency are primary contrib-
Figure 8. LPS induces cirrhosis and carcinoma in $\mathrm{Clk}^{419 / 419} \mathbf{A p o e}^{-/-}$mice. Male (10-month-old) $\mathrm{Cl}^{419 / 419} \mathrm{Apoe}^{-/-}$and $A$ poe ${ }^{-/-}$mice fed a chow diet were injected i.p. with LPS $(0.25 \mathrm{mg} / \mathrm{kg}) 3$ times on alternate days. Two months after the last injection, plasma and liver were collected ( $n=6$ per group). Other animals were used for $\left[{ }^{3} \mathrm{H}\right] \mathrm{OA}$ or carbon-14-labeled $\mathrm{OA}\left({ }^{1{ }^{4} \mathrm{C}} \mathrm{C} \mathrm{OA}\right)$ uptake and oxidation ( $n=6$ per group), respectively, or for Dil-labeled AcLDL uptake ( $n=6$ per group). (A) Livers from LPS-injected CI ${ }^{419 / 419}$ Apoe $^{-/-}$mice showed macronodular cirrhosis. (B) Liver triglyceride decreased but liver TBARS levels increased in LPS-injected $C \mathrm{~K}^{419 / \Delta 19}$ Apoe $^{-/-}$mice. Mean $\pm \mathrm{SD}$; ${ }^{* *} P<0.001$ unpaired Welch's 2-tailed $t$ test. (C) Plasma ALT levels were higher in LPS-injected $C{ }^{1 / 19 / \Delta 19}$ $A$ poe $^{-/-}$mice. In contrast, plasma $\beta$-HB concentrations were lower in LPS-injected $C \mathrm{~K}^{419 / 419}$ Apoe ${ }^{-1-}$ mice. Mean \pm SD; ${ }^{*} P<0.05,{ }^{* * *} P$ $<0.001$, unpaired Welch's 2-tailed $t$ test. (D) Hepatic uptake of [ $\left.{ }^{3} \mathrm{H}\right] \mathrm{OA}$ was lower in LPS-injected Clk ${ }^{119 / 419}$ Apoe $^{-/-}$mice. Mean \pm SD; ${ }^{* *} P<0.01$, unpaired Welch's 2-tailed $t$ test. (E) Dil-labeled AcLDL uptake was high after 2 hours in livers of $\mathrm{Cl}^{119 / 419} \mathrm{Apoe}^{-/-}$mice injected with Dil-labeled AcLDL $(5 \mu \mathrm{g} / \mathrm{mL})$. Mean \pm $\mathrm{SD}$; ${ }^{* * *} P<0.001$, unpaired Welch's 2-tailed $t$ test. (F) Fatty acid oxidation was decreased in LPS-injected $\mathrm{Cl}^{419 / \Delta 19} \mathrm{Apoe}^{-/-}$mice. Mean $\pm \mathrm{SD}$ ${ }^{*} P<0.001$, unpaired Welch's 2 -tailed $t$ test. (C) Livers were stained with Oil Red 0 (top), anti-macrophage antibodies (middle), and H\&E (bottom). Data are representative of 2 experiments. uting factors to cirrhosis. $\mathrm{Clk}^{419 / 419} \mathrm{Apoe}^{-/-}$mice injected with LPS or $\mathrm{CoCl}_{2}$ developed cirrhosis and HCC.

Hepatic triglycerides increased in $C l k^{119 / 419}$ mice with age and Western diet (Supplemental Figure 11B). LPS and $\mathrm{CoCl}_{2}$ injections reduced hepatic triglyceride in these mice. The $\mathrm{Clk}^{419 / 419} \mathrm{Apoe^{-/- }}$ livers had lower triglyceride, and these levels decreased further after LPS and $\mathrm{CoCl}_{2}$ injections. Hepatic fatty acid uptake increased with age and Western diet in both $\mathrm{Clk}^{119 / 419}$ and $\mathrm{Clk}^{119 / 419} \mathrm{Apoe}^{-/-}$ 
A

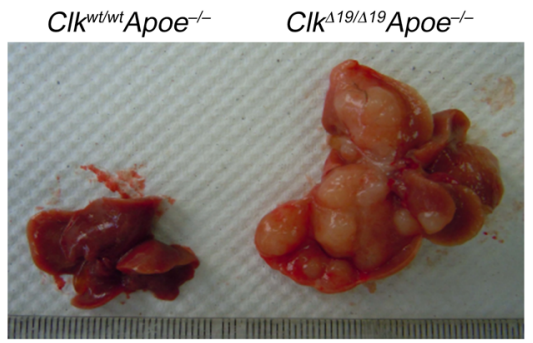

B

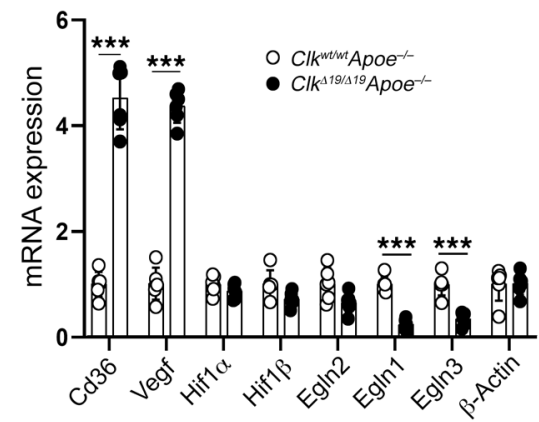

C

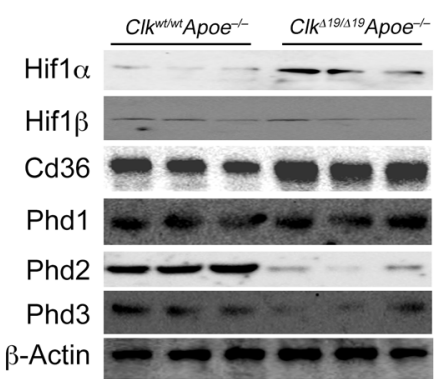

$\mathbf{F}$

F
0
0
$\bar{d}$
$\frac{\alpha}{\overline{0}}$

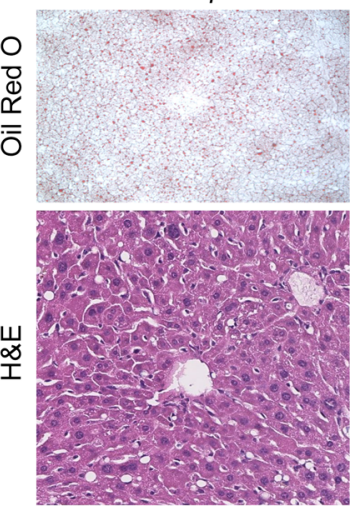

$\mathrm{Clk}^{\Delta 19 / 19} \mathrm{Apoe}^{-1}$

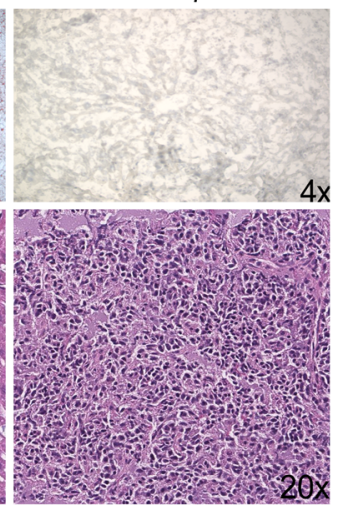

D
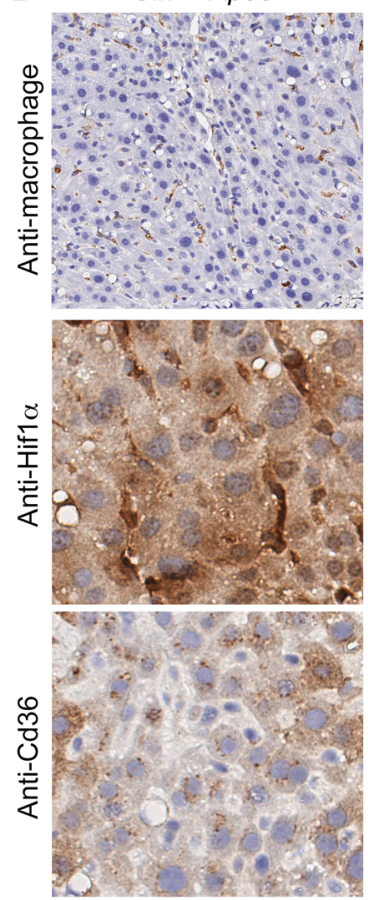

E

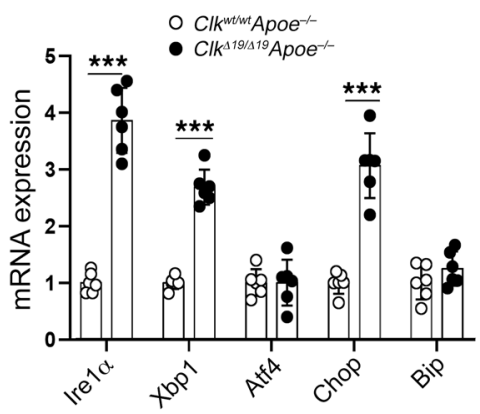

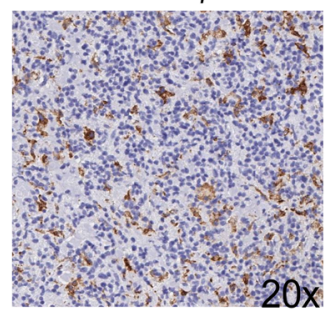
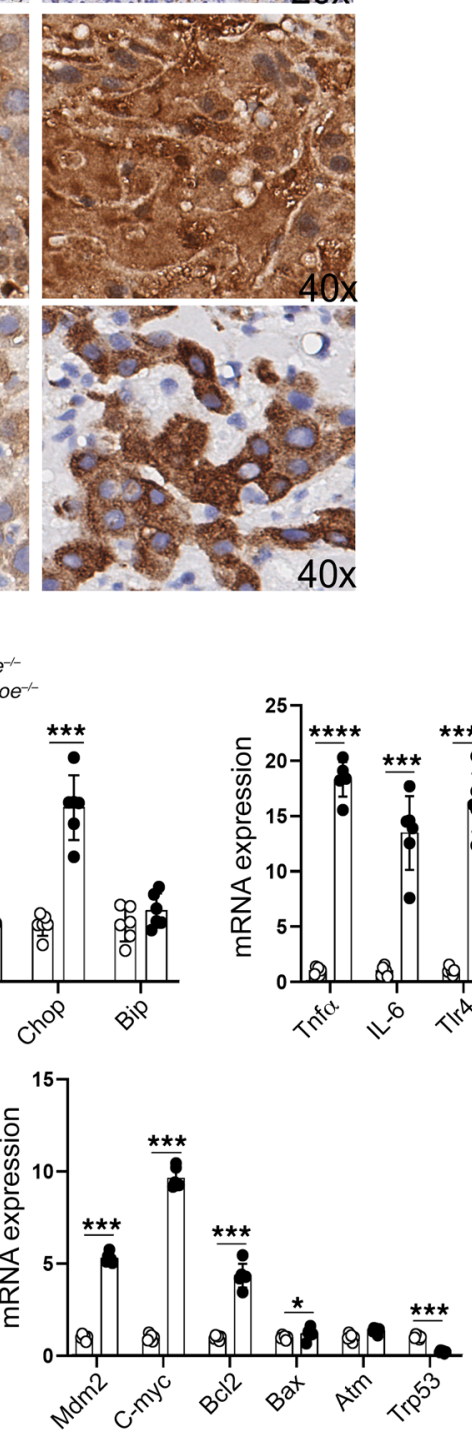

Figure 9. $\mathrm{CoCl}_{2}$ induces $\mathrm{HCC}$ in $\mathrm{Clk}^{419 / 419} \mathbf{A p o e}^{-/-}$mice. Male $\mathrm{Clk}^{419 / 419} \mathrm{Apoe}^{-/-}$and Apoe $\mathrm{e}^{-/}$(10-month-old, ad libitum chow-fed) mice were injected i.p. 3 times on alternate days with $\mathrm{CoCl}_{2}\left(30 \mathrm{mg} / \mathrm{kg}\right.$ ) and continued on the same diet for an additional 2 months. (A) $\mathrm{Cl}^{419 / 419} \mathrm{Apoe}^{-/-}$mice injected with CoCl developed HCC. (B) Expression of genes in hypoxia and Cd36. Mean \pm SD; ${ }^{* * *} P<0.001$, multiple $t$ tests. (C) HIF1 $\alpha$ and CD36 protein levels increased in livers of $\mathrm{CoCl}_{2}$-injected $\mathrm{Clk}^{419 / 419} \mathrm{Apoe}^{-/-}$mice. (D) $\mathrm{HIF1} \alpha$ and $\mathrm{CD} 36$ protein levels and macrophages increased in livers of $\mathrm{CoCl}_{2}$-injected $\mathrm{Cl}^{419 / 419} \mathrm{Apoe}^{-/-}$mice. Data are representative of 2 experiments. (E) mRNA levels of selected genes in ER stress, inflammatory response, and carcinogenesis. Mean \pm SD; ${ }^{*} P<0.05$, ${ }^{* * *} P$ $<0.001,{ }^{* * * *} P<0.0001$, multiple $t$ tests. (F) Livers were stained with Oil Red $\mathrm{O}$ stains (top) and H\&E stains (bottom). Livers of CoCl ${ }_{2}$-injected $\mathrm{Cl}^{419 / 419}$ $A p o e^{-/-}$mice showed less lipid staining and more hyperplasia. Data are representative of 2 experiments.

mice (Supplemental Figure 11C). Hepatic TBARS increased in both $C l k^{119 / 419}$ and $C l k^{119 / 419} A_{p o e^{-/-}}$mice in early stages of disease, reached maximum levels in cirrhotic livers, and remained high in HCC (Supplemental Figure 11D). It is likely that high hepatic
TBARS is a good indicator of a cirrhotic liver in mice. Plasma ALT levels increased in both animal models with age, Western diet, and LPS/ $\mathrm{CoCl}_{2}$ treatments (Supplemental Figure 11E); therefore, ALT could be a good marker for severity of the disease. 

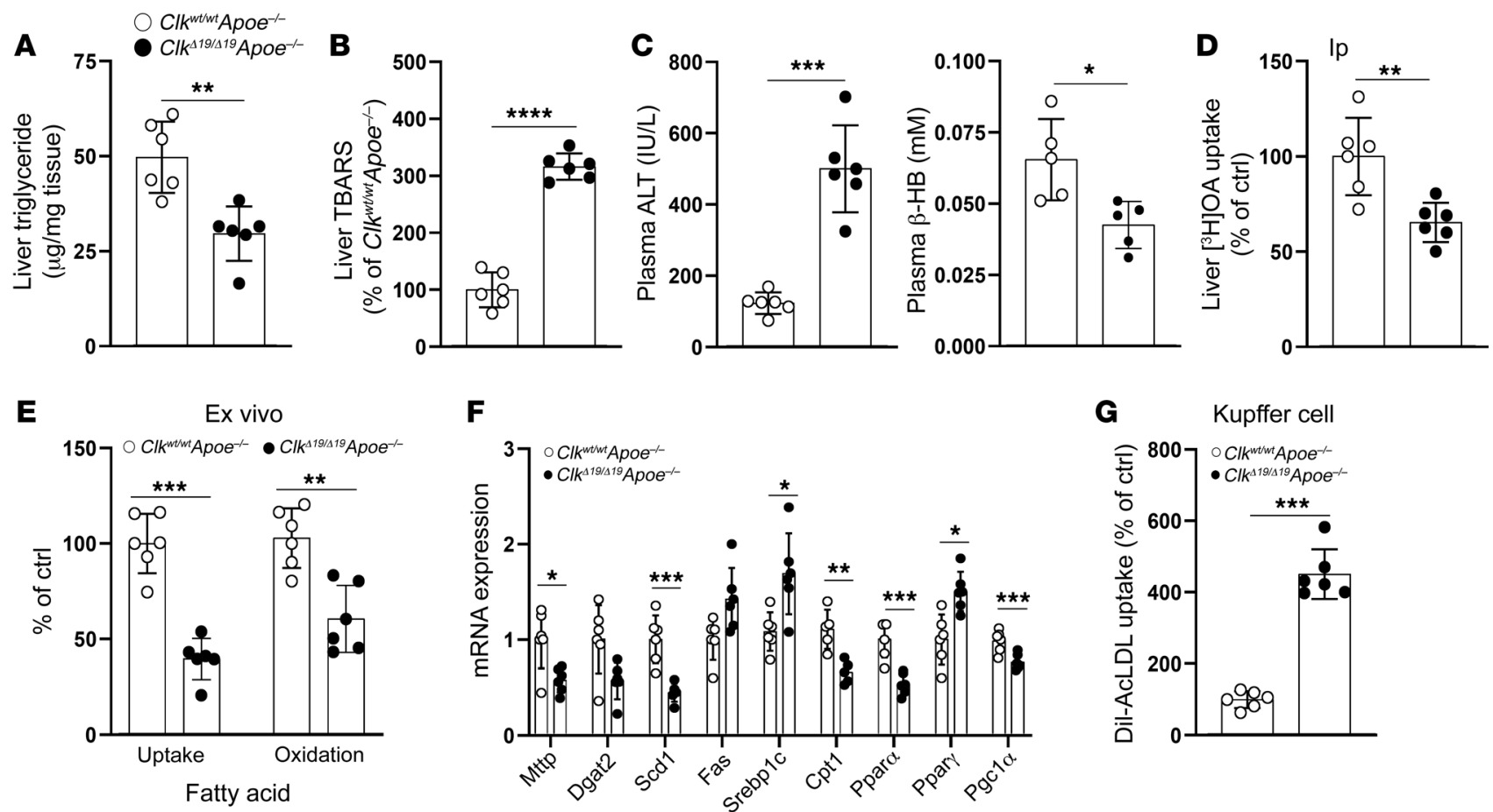

$\mathbf{F}$

G Kupffer cell
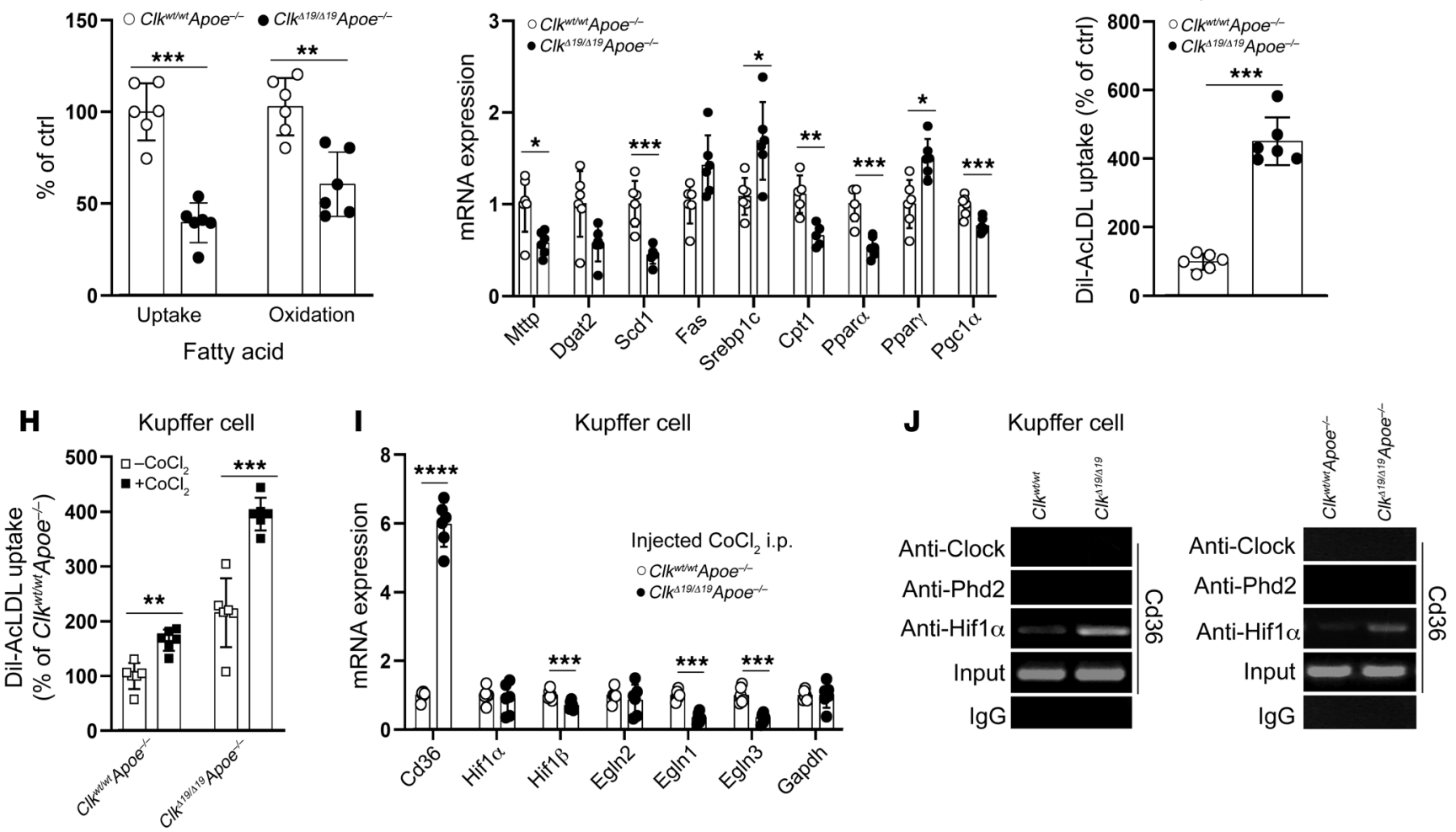

Figure 10. $\mathrm{CoCl}_{2}$ induces HIF1a in macrophages in $\mathrm{Clk}^{\mathbf{4 1 9 / 4 9}} \mathbf{A p o e}^{-/-}$mice. Animals were treated with $\mathrm{CoCl}_{2}$ as described in Figure 9 and used to collect tissues ( $n=6$ per group), to study hepatic $\left[{ }^{3} \mathrm{H}\right] \mathrm{OA}$ uptake or $\left[{ }^{14} \mathrm{C}\right] \mathrm{OA}$ oxidation ( $n=6$ per group), or for isolation of Kupffer cells ( $n=6$ per group). (A and B) Triglyceride levels decreased (A) but TBARS increased (B) in livers of $\mathrm{CoCl}_{2}$-injected $\mathrm{Cl}^{419 / 419} \mathrm{Apoe}^{-/-}$mice. (C) Plasma ALT levels increased in CoCl 2 -injected

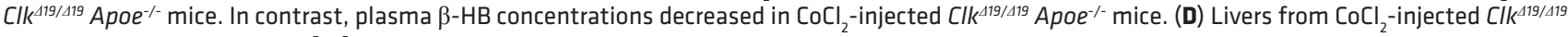
$A$ Ape $^{-/}$mice assimilated less [ $\left.{ }^{3} \mathrm{H}\right] \mathrm{OA}$ than controls. (E) Liver slices from $\mathrm{CoCl}_{2}$-injected $\mathrm{Cl}^{419 / 419} \mathrm{Apoe}^{-/-}$mice were used to study fatty acid uptake and oxidation. (F) Expression of lipoprotein assembly and $\beta$-oxidation genes was reduced in $\mathrm{CoCl}_{2}$-injected $\mathrm{Clk}^{419 / \Delta 19} \mathrm{Apo} e^{-/-}$mice. Mean $\pm \mathrm{SD}$; ${ }^{*} P<0.05$, ${ }^{* *} P<$ 0.01 , ${ }^{* *} P<0.001,{ }^{* * *} P<0.0001$, multiple $t$ tests. (C) Kupffer cells isolated from CoCl -injected $\mathrm{Cl}^{119 / 419} \mathrm{Apoe}^{-/-}$mice took up more Dil-labeled AcLDL (5 $\mu \mathrm{g} / \mathrm{mL})$. Kupffer cells were incubated with Dil-labeled AcLDL $(5 \mu \mathrm{g} / \mathrm{mL})$ for 4 hours. Cells were washed, lipids were extracted, and dye was measured at 485 nm. (H) Kupffer cells isolated from $\mathrm{CoCl}_{2}$-injected $\mathrm{Cl}^{\mathrm{wt} / \mathrm{wt}} A$ poe ${ }^{-/-}$and $\mathrm{Clk}^{419 / 419} A$ poe ${ }^{-/-}$mice were incubated with Dil-AcLDL. Mean $\pm \mathrm{SD}$; ${ }^{* * *} P<0.001,2-$ way ANOVA, Šidák's multiple-comparisons test. (I) mRNA levels of different genes in isolated Kupffer cells from CoCl ${ }_{2}$-injected mice. Mean \pm SD; ${ }^{* * *} P<0.001$ ${ }^{* * * *} P<0.0001$, multiple $t$ tests. (J) ChIP assays were performed in Kupffer cells isolated from livers of indicated mice to study the binding of HIF1 $\alpha$ to the Cd36 promoter. Data are representative of 2 experiments.

$C l k^{119 / 419}$ mice showed reduced expression of $C p t 1$ (Supplemental Figure 11F). It is likely that low Cpt1 mRNA levels in $\mathrm{Clk}^{19 / 419}$ mice may be an early indicator of impaired fatty acid $\beta$-oxidation that could contribute to steatosis. We observed that Fas and Mttp mRNA increased in $C l k^{119 / 119}$ mice with age and a Western diet and remained high after other interventions. Surprisingly, older $\mathrm{Clk}^{419 / 119}$ Apoe $^{-/-}$mice injected with LPS or $\mathrm{CoCl}_{2}$ had reduced Fas and Mttp expression. Thus, in advanced diseases, hepatic lipid synthesis and lipoprotein assembly might be downregulated.
In general, $C d 36$ mRNA levels increase with age, Western diet, and $\mathrm{CoCl}_{2}$ injection in $\mathrm{Clk}^{119 / 119}$ mice (Supplemental Figure $11 F)$. Our studies suggest that, in early stages, CD36 increases in hepatocytes and is associated with increased fatty acid uptake. In advanced diseases, CD36 increases in macrophages and may be associated with increased uptake of modified lipoproteins.

Both $\mathrm{Clk}^{119 / 419}$ and $\mathrm{Clk}^{119 / 119} \mathrm{Apoe}^{-/-}$mice showed increases only in mRNA levels of Ire1 $\alpha$ and its downstream target Xbp1 (Supplemental Figure 12). Also, diets and other interventions failed to 
induce other arms of the ER stress pathway. Increases in Ire1a pathway may contribute to increases in plasma ALT. We have shown that the Ire1 $\alpha$ pathway may increase expression of transaminases via the JNK pathway (29). These studies suggest that CLOCK mutant protein selectively upregulates the Ire1 $\alpha$ pathway.

$C l k^{419 / 419}$ mice fed different diets and challenged with LPS or $\mathrm{CoCl}_{2}$ showed modest increases (Supplemental Figure 11G) in Tlr 4 and Il6 mRNA. However, $\mathrm{Clk}^{419 / 419} \mathrm{Apoe}^{-/-}$mice challenged with LPS or $\mathrm{CoCl}_{2}$ showed greater increases ( $>10$-fold) compared with controls (Supplemental Figure 11G). Genes involved in carcinogenesis did not differ between control and $C l k^{419 / \Delta 19}$ mice (Supplemental Figure $11 \mathrm{H}$ ), but they were modestly increased or decreased in older Clk $\mathrm{k}^{419 / 419} \mathrm{Apoe}^{-/-}$mice. However, LPS (approximately 5-fold change) and $\mathrm{CoCl}_{2}$ (approximately 5- to 10-fold change) significantly increased $C-m y c$ and $B c l 2$ genes but decreased Trp53 in $\mathrm{Clk}^{419 / 419} \mathrm{Apoe}^{-/-}$mice. Thus, changes in the expression of inflammation and cancer genes are associated with advanced liver diseases, such as cirrhosis and HCC, in $\mathrm{Clk}^{419 / 419} \mathrm{Apoe}^{-/-}$mice.

In these studies, we did not see any change in HIF1 $\alpha$ mRNA levels. However, a constant feature of all $C^{4} k^{119 / \Delta 19}$ and $C l k^{119 / \Delta 19}$ Apoe $^{-/-}$mice was age-dependent reduction in Egln mRNA levels (Supplemental Figure 11I). Therefore, reduction in Phd mRNA levels and associated increases in HIF1 $\alpha$ protein levels could be significant contributing factors for age-dependent liver disease progression in $C l k^{119 / 419}$ mice.

\section{Discussion}

Here, we report that $C l k^{419 / 419}$ mice on WT and $A p o e^{-/-}$backgrounds exhibit different stages of NAFLD. The progression of liver diseases is accelerated when $C l k^{419 / 419}$ mice are fed a high-cholesterol diet or in the presence of apoE deficiency. Injection of LPS to cholesterol-fed $C l k^{419 / \Delta 19}$ mice enhanced the inflammatory response and steatohepatitis; the same injection to $\mathrm{Clk}^{119 / 419} \mathrm{Apoe}^{-/-}$mice induced cirrhosis. Injection of $\mathrm{CoCl}_{2}$ in $\mathrm{Clk}^{419 / 419}$ and $\mathrm{Clk}^{119 / 419}$ $\mathrm{Apoe}^{-/-}$mice induced cirrhosis and HCC, respectively. Molecular studies revealed that hepatic CD36 increased in these mice. Mechanistic studies identified HIF1 $\alpha$ as a major regulator of CD36 and a key transcription factor that contributes to disease progression. Knockdown of HIF1 $\alpha$ attenuated disease progression in $\mathrm{Clk}^{119 / 419}$ mice. We showed that CLOCK regulates HIF1 $\alpha$ protein levels by binding to the E-boxes in the promoters and modulating the expression of PHD proteins that regulate HIF1 $\alpha$ protein stability. In CLOCK deficiency, PHD levels are low, and HIF1 $\alpha$ levels are high. Under these conditions, HIF1 $\alpha$ binds to the $C d 36$ promoter to increase expression of CD36 and uptake of fatty acids by the liver. Thus, a regulatory mechanism involving circadian CLOCK, hypoxia signaling, and lipid metabolism protects against NAFLD.

Age-dependent studies in chow-fed $C l^{419 / 419}$ mice provided some clues about the development of steatosis and steatohepatitis. Adolescent mice ( $<3$ months old) did not accumulate significant amounts of hepatic triglyceride. However, these mice showed increased expression of genes in lipid synthesis and reduced expression of genes in $\beta$-oxidation. A combination of these changes should have caused steatosis. However, these mice also had increased expression of genes in lipoprotein assembly and secretion; we have shown previously that these mice produce more lipoproteins and display hypertriglyceridemia $(15,16,30$,
31). Based on our current and previous studies, we suggest that CLOCK deficiency affects several pathways. It upregulates lipid synthesis and inhibits $\beta$-oxidation. It also favors lipoprotein production to avoid steatosis and results in hypertriglyceridemia in young mice. However, in older mice, this balance is shifted toward more hepatic lipid accumulation.

Young $\mathrm{Clk}^{119 / \Delta 19} \mathrm{Apoe}^{-/-}$mice develop hepatosteatosis; however, older mice challenged with LPS or $\mathrm{CoCl}_{2}$ have lower hepatic triglyceride levels and develop cirrhosis and HCC. Thus, hepatic disease starts with increased lipid uptake and accumulation and culminates with increased inflammatory and carcinogenic responses.

These studies identified 3 pathways - circadian rhythms, lipid uptake, and hypoxia - and 4 proteins - CLOCK, apoE, CD36, and HIF $1 \alpha$ - that play roles in the pathogenesis of NAFLD. First, CLOCK is an important regulator of lipid uptake and hypoxia response under normoxic conditions by modulating the expression of PHD proteins. Second, apoE deficiency, along with CLOCK deficiency, contributes to liver disease. Third, CD36 plays a role in the uptake of fatty acids and the development of steatosis. Fourth, HIF1 $\alpha$ regulates CD36 expression. Thus, circadian control mechanisms regulate lipid metabolism via hypoxia signaling.

Normally, HIF1 $\alpha$ protein levels are low and increase under hypoxic conditions. HIF1 $\alpha$ plays a role in fibrosis and in cancer progression $(9,32,33)$ because of the presence of hypoxic conditions in fibrotic and cancerous liver tissues. Our studies point to involvement of HIF1 $\alpha$ in the early stages of liver disease, such as steatosis and NASH, before the onset of hypoxic conditions. We propose that, under normoxic conditions, HIF1 $\alpha$ is regulated by circadian rhythms, and increased expression of HIF1 $\alpha$ might be a contributing factor for the pathogenesis of liver diseases when circadian rhythms are disrupted.

We identified HIF1 $\alpha$ as a regulator of lipid uptake. In addition, we observed that increases in HIF1 $\alpha$ were associated with reduced fatty acid oxidation. This is consistent with studies that showed that HIF1 $\alpha$ and HIF2 $\alpha$ reduced fatty acid oxidation under hypoxic conditions (34).

Our study was not designed to address the role of different liver cells in disease progression. We think all liver cells play an integral role in the development of NAFLD. We provide evidence for the involvement of hepatocytes and Kupffer cells using isolated cells. Both these cells express HIF1 $\alpha$ and CD36 (34). In addition, hepatic endothelial cells also most likely play a role in disease progression.

The relevance of mouse models to human diseases is highly debated. Nevertheless, mouse models provide some understanding about molecules and pathways that could play roles in disease progression $(35,36)$. Here, we provide mouse models that show different stages of NAFLD. The observations made here in $\mathrm{Cl}^{119 / \Delta 19}$ mice might be specific to these mice because of the expression of the dominant-negative CLOCK mutant protein. Conversely, these observations could be indirectly related to changes in circadian rhythms. Additional mouse models with disruptions in other circadian genes are needed to parse whether CLOCK deficiency and/ or disruptions in circadian rhythms increase the risk for NAFLD.

It remains to be determined whether biochemical and molecular mechanisms described in these mouse models are also altered in other mouse models of NAFLD and in humans. If similar mechanisms are found in humans, these mouse models could 
identify molecules that play critical roles in transition from one disease stage to another and different drugs that can prevent and reverse these diseases.

In summary, we demonstrate that normal CLOCK functions to protect against NAFLD. BMAL1 has been shown to protect against alcoholic liver disease (37). Thus, circadian genes, in general, may protect against both alcoholic and nonalcoholic liver diseases. In the absence of the normal CLOCK regulatory function, livers accumulate lipids and a cascade of events occurs, resulting in steatohepatitis and cirrhosis with age. The development of these pathologies is augmented by additional insults, such as apoE deficiency, LPS, and $\mathrm{CoCl}_{2}$. Thus, deregulation of the CLOCK function might predispose mice to NAFLD. Different mouse models described here may be useful to explore additional molecular, biochemical, and physiologic pathways and to discover drugs that prevent liver diseases.

\section{Methods}

Fresh stock solutions of $0.4 \mathrm{M} \mathrm{CoCl}_{2}$ or 0.25 M DMOG (Supplemental Table 1) were prepared in $0.9 \% \mathrm{NaCl}$, filtered, and added to the medium to obtain desired final concentrations. For i.p. injections, stock was prepared in sterile PBS. LPS was dissolved in PBS to obtain a concentration of $1 \mathrm{mg} / \mathrm{mL}$. [9,10- $\left.{ }^{3} \mathrm{H}(\mathrm{N})\right]$ Oleic acid $\left(\left[{ }^{3} \mathrm{H}\right] \mathrm{OA} ; 1 \mu \mathrm{Ci} /\right.$ $\mathrm{mL}, 37 \mathrm{MBq}$, catalog NET289001MC), carbon-14-labeled OA (2.183 GBq/mmol, catalog PEC317150UC), and carbon-14-labeled palmitic acid (PA; $1 \mu \mathrm{Ci} / \mathrm{mL}, 1.85 \mathrm{MBq}$, catalog NEC534050UC) were obtained from PerkinElmer. Adenoviruses expressing shRNA against mouse HIF1 $\alpha\left(1 \times 10^{11} \mathrm{PFU} / \mathrm{mL}\right)$ were from Vector Biolabs.

Animals. C57BL/6J Clkwt/wt, $\mathrm{Clk}^{119 / 419}$, and $\mathrm{Apoe}^{-/-}$mice were from The Jackson Laboratory. $C l k^{419 / w t}$ mice were bred to obtain $C l k^{w t / w t}$ and $C l k^{419 / 419}$ mice for experiments. $C l k^{419 / 419}$ and $\mathrm{Apoe}^{-/-}$mice were interbred to obtain male and female $\mathrm{Clk}^{419 / w t} A p o e^{-/-}$mice. These mice were bred to obtain $\mathrm{Apoe}^{-/-}$and $\mathrm{Clk}^{119 / 419} \mathrm{Apoe}^{-/-}$siblings for experiments (15). All mice were fed a chow diet (Supplemental Table 2) unless stated otherwise. To study the effects of different diets, age- and sex-matched littermates were placed on either a cholate-containing high-fat diet (Harlan Teklad, TD88051) or a high-cholesterol Western diet (Supplemental Table 2). In some experiments, mice were injected via tail vein with a single dose of lentiviruses expressing shRNA HIF1 $\alpha\left(1 \times 10^{9} \mathrm{PFU}\right)$ or control viruses harboring no transgene (shRNA control). $\mathrm{CoCl}_{2}$ and LPS were injected i.p. on alternate days, as described in the figure legends.

Plasma and tissue lipid analysis. Blood samples were obtained from the tail vein after a 4 -hour fast. Total plasma triglycerides, cholester$\mathrm{ol}, \beta-\mathrm{HB}$, and free fatty acids were assayed using commercial kits (16, 17, 38). Plasma ALT and AST levels were measured using kits from Wako Pure Chemical Industries (38). Hepatic lipid peroxidation was assessed by measurement of TBARS (15-17, 38). Liver tissues (30-50 $\mathrm{mg}$ ) were homogenized in buffer $\mathrm{K}$, as previously described $(16,30)$. Lipids were extracted with chloroform/methanol and quantified using commercial kits (16).

Mouse hepatocytes and Kupffer cells. We isolated primary hepatocytes or Kupffer cells from different mice by collagenase perfusion, as previously described $(17,39,40)$. To obtain hepatocytes and Kupffer cells, mouse livers were perfused through the portal vein with $25 \mathrm{~mL}$ of Hanks solution containing $2.5 \mathrm{mM} \mathrm{EGTA}$ at $37^{\circ} \mathrm{C}$ at a rate of $20 \mathrm{~mL}$ per 5 minutes. Next, $100 \mathrm{~mL}$ of buffer containing $0.05 \%$ collagenase was recirculated at a rate of $20 \mathrm{~mL}$ per 5 minutes through the liver for approximately 18 minutes. Then, livers were cut into approximately $1-\mathrm{mm}^{3}$ pieces and incubated with $0.1 \%$ type IV collagenase at $37^{\circ} \mathrm{C}$ for 30 minutes for further digestion. The incubation cocktail was blown gently with a pipette to help cell dispersion. The cell suspension was filtered through a $75-\mu \mathrm{m}$ cell strainer, and the filtrate was centrifuged and resuspended in DMEM supplemented with 10\% FBS and 1\% penicillin-streptomycin. Cells $\left(1 \times 10^{6}\right.$ per well $)$ were plated in 6-well plates in DMEM supplemented with 10\% FBS and 20 mM HEPES. Cells reached confluence in 2 days and then were either incubated with $\left[{ }^{3} \mathrm{H}\right] \mathrm{OA}$ or transfected to overexpress or knock down genes of interest. Isolated Kupffer cells were placed in DMEM with 10\% FBS plus $25 \% \mathrm{~L}$ cell-conditioned medium (17).

Uptake of fatty acids by cells in culture. Hepatocytes or Kupffer cells from C57BL/6J mice were transfected with siClk or siCtrl for 48 hours and then incubated with $\left[{ }^{3} \mathrm{H}\right] \mathrm{OA}$ in serum-free DMEM at $37^{\circ} \mathrm{C}$ for 1 hour. Kupffer cells from different mice were placed in DMEM with $10 \%$ FBS for 1 week; then cells were incubated with $\left[{ }^{3} \mathrm{H}\right] \mathrm{OA}$ $(0.5 \mu \mathrm{Ci} / \mathrm{mL})$ in FBS-free DMEM at $37^{\circ} \mathrm{C}$ for 1 hour. Radioactivity in the medium and cells was quantified by scintillation counting. The assays were performed in quadruplicate, and results are presented as percentage uptake (15-17, 31).

Fatty acid oxidation by cells in culture and in liver slices. Fresh liver slices $\left(<10 \mathrm{mg}\right.$ each) were incubated with $\left[{ }^{14} \mathrm{C}\right] \mathrm{PA}(0.2 \mu \mathrm{Ci} / \mathrm{mL})$ or $\left[{ }^{14} \mathrm{C}\right] \mathrm{OA}(0.2 \mu \mathrm{Ci} / \mathrm{mL})$ for 2 hours, and radiolabeled $\mathrm{CO}_{2}$ was trapped on a filter paper soaked with phenylethylamine. In cells, oxidation was determined by quantification of ${ }^{14} \mathrm{C}$-acid-soluble $\beta$-oxidation products after 1 -hour incubations. Measurements were performed as previously described (41).

Liver fatty acid uptake in vivo. Mice were fasted for 4 hours and injected i.p. with $1 \mu \mathrm{Ci} /$ mouse of $\left[{ }^{3} \mathrm{H}\right] \mathrm{OA}$ in $0.25 \mathrm{~mL}$ of PBS. Blood $(20 \mu \mathrm{L})$ was obtained from the tail vein at different times, and the liver was collected at the end. Plasma and liver pieces were used for liquid scintillation counting. Liver counts were normalized to $1 \mathrm{mg}$ of liver protein.

Tissue preparation and histologic examination. Fresh liver tissues were cut, mixed with OCT compound, rapidly frozen in liquid nitrogen, and stored at $-80^{\circ} \mathrm{C}$. Frozen sections were cut $(6 \mu \mathrm{m}$ thick $)$ and used for Oil Red O and H\&E staining. TUNEL staining was conducted using a kit (Roche). Liver sections were also formalin fixed and paraffin embedded. For immunohistochemistry, fixed tissues were sent to HistoWiz.

Western blot analysis. Liver pieces were homogenized in lysis buffer. Proteins $(20 \mu \mathrm{g} /$ lane $)$ were separated under nonreducing conditions using SDS-PAGE, transferred to nitrocellulose membranes, and blocked for 2 hours in TBS-Tween-20 buffer containing 5\% nonfat dry milk at room temperature. The blots were washed 3 times and incubated overnight at $4^{\circ} \mathrm{C}$ in the same buffer with a primary antibody (1:100 to $1: 1000$ dilution), washed, and then incubated with mouse HRP-conjugated secondary antibody (1:1000 to 1:4000) in 1.0\% nonfat dry milk for 1 hour at room temperature. Immune reactivity was detected by chemiluminescence (15-17, 38).

Quantitative real-time PCR. Liver tissues were stored at $-80^{\circ} \mathrm{C}$, and total RNA was isolated using Trizol (Invitrogen). Isolated total RNA was reverse-transcribed $(15-17,38)$ and used for real-time PCR. Primers used are shown in Supplemental Table 3. 18S rRNA was used as the reference gene. The mRNA expression level of Arppo was used as the control (17). 
ChIP assay. Liver tissues or primary cells were subjected to ChIP using the ChIP assay kit (USB, catalog 78460) according to the instructions; specific goat polyclonal antibodies used are described in Supplemental Table 1. DNA samples recovered after immunoprecipitation were subjected to PCR using gene-specific primers (Supplemental Table 3), and subjected to agarose gel electrophoresis. For negative controls, ChIP was performed in the absence of antibody or in the presence of rabbit IgG. These experiments were repeated 3-4 times, and similar results were obtained. Data from 1 individual representative experiment are provided.

Lipoprotein production in vivo. Mice (fasted for 5 hours from $10 \mathrm{am}$ ) were injected i.p. with $0.5 \mathrm{~mL}$ of poloxamer 407 in PBS $(1 \mathrm{mg} / \mathrm{mouse}$ body weight, 1:6, vol/vol), and blood was collected at different times. Plasma was used for liquid scintillation counting and lipid measurements. Triglyceride synthesis and fatty acid oxidation experiments were performed as previously described (42).

Statistics. Statistical analysis was performed using GraphPad Prism software. Data are presented as means \pm SD. Statistical testing was performed using Student's $t$ test. Multiple comparisons between groups were performed using 1-way or 2-way ANOVA followed by indicated post-tests (GraphPad Prism). Differences were considered statistically significant when $P$ was less than 0.05 .

Study approval. Animal protocols were approved by the Animal Care and Use Committees of SUNY Downstate Medical Center and NYU Winthrop Hospital, Mineola, New York, USA.

\section{Author contributions}

$\mathrm{XP}$ designed and performed experiments, analyzed data, interpreted results, discussed implications, and wrote and critically evaluated the manuscript. MMH supervised the project, interpreted results, discussed implications, obtained funding, and wrote the manuscript. JQ performed cryosectioning and staining of the tissues.

\section{Acknowledgments}

This work was supported in part by NIH grants DK121490 and DK081879; VA Merit Award BX001728 to MMH; and NIH grant HL137912 and American Heart Association Grant-in-Aid 16GRNT30960027 to XP. The contents of this paper do not represent the views of the Department of Veterans Affairs or the US Government. The content is solely the responsibility of the authors and does not necessarily represent the official views of the NIH. We thank Wei Quan for electron microscopy.

Address correspondence to: M. Mahmood Hussain, Department of Foundations of Medicine, New York University Long Island School of Medicine, Research and Academic Building, 101 Mineola Blvd, Suite 3-041, Mineola, New York 11501 USA. Email: Mahmood.hussain@ nyulangone.org. Or to: Xiaoyue Pan, Department of Foundations of Medicine, New York University School of Medicine, Research and Academic Center, 101 Mineola Blvd, Suite 4-002, Mineola, New York 11501, USA. Email: xiaoyue.pan@nyulangone.org.
1. Diehl AM, Day C. Cause, pathogenesis, and treatment of nonalcoholic steatohepatitis. $\mathrm{NEngl}$ JMed. 2017;377(21):2063-2072.

2. Friedman SL, Neuschwander-Tetri BA, Rinella M, Sanyal AJ. Mechanisms of NAFLD development and therapeutic strategies. Nat Med. 2018;24(7):908-922.

3. Bessone F, Razori MV, Roma MG. Molecular pathways of nonalcoholic fatty liver disease development and progression. Cell Mol Life Sci. 2019;76(1):99-128.

4. Mazzoccoli G, De Cosmo S, Mazza T. The biological clock: a pivotal hub in non-alcoholic fatty liver disease pathogenesis. Front Physiol. 2018;9:193.

5. Shetty A, Hsu JW, Manka PP, Syn WK. Role of the circadian clock in the metabolic syndrome and nonalcoholic fatty liver disease. Dig Dis Sci. 2018;63(12):3187-3206.

6. Turek FW, et al. Obesity and metabolic syndrome in circadian Clock mutant mice. Science. 2005;308(5724):1043-1045.

7. Wang GL, Jiang BH, Rue EA, Semenza GL. Hypoxia-inducible factor 1 is a basic-helixloop-helix-PAS heterodimer regulated by cellular O2 tension. Proc Natl Acad Sci U S A. 1995;92(12):5510-5514.

8. Semenza GL. HIF-1 mediates metabolic responses to intratumoral hypoxia and oncogenic mutations. JClin Invest. 2013;123(9):3664-3671.

9. Schito L, Semenza GL. Hypoxia-inducible factors: master regulators of cancer progression. Trends Cancer. 2016;2(12):758-770.

10. Koivunen P, Kietzmann T. Hypoxia-inducible factor prolyl 4-hydroxylases and metabolism. Trends Mol Med. 2018;24(12):1021-1035.

11. Fong GH, Takeda K. Role and regulation of prolyl hydroxylase domain proteins. Cell Death Differ. 2008;15(4):635-641.

12. Wu Y, et al. Reciprocal regulation between the circadian clock and hypoxia signaling at the genome level in mammals. Cell Metab. 2017;25(1):73-85.

13. Hogenesch JB, Gu YZ, Jain S, Bradfield CA. The basic-helix-loop-helix-PAS orphan MOP3 forms transcriptionally active complexes with circadian and hypoxia factors. Proc Natl Acad Sci U S A . 1998;95(10):5474-5479.

14. Peek CB, et al. Circadian clock interaction with HIF1 $\alpha$ mediates oxygenic metabolism and anaerobic glycolysis in skeletal muscle. Cell Metab. 2017;25(1):86-92

15. Pan X, Jiang XC, Hussain MM. Impaired cholesterol metabolism and enhanced atherosclerosis in clock mutant mice. Circulation. 2013;128(16):1758-1769.

16. Pan X, Zhang Y, Wang L, Hussain MM. Diurnal regulation of MTP and plasma triglyceride by CLOCK is mediated by SHP. Cell Metab. 2010;12(2):174-186.

17. Pan X, Bradfield CA, Hussain MM. Global and hepatocyte-specific ablation of Bmal1 induces hyperlipidaemia and enhances atherosclerosis. Nat Commun. 2016;7:13011.

18. Mwaikambo BR, Yang C, Chemtob S, Hardy P. Hypoxia up-regulates CD36 expression and function via hypoxia-inducible factor-1- and phosphatidylinositol 3-kinase-dependent mechanisms. J Biol Chem. 2009;284(39):26695-26707.

19. Crucet M, Wüst SJ, Spielmann P, Lüscher TF, Wenger RH, Matter CM. Hypoxia enhances lipid uptake in macrophages: role of the scavenger receptors Lox1, SRA, and CD36. Atherosclerosis.
2013;229(1):110-117.

20. Ortiz-Masià D, et al. Induction of CD36 and thrombospondin-1 in macrophages by hypoxia-inducible factor 1 and its relevance in the inflammatory process. PLoS One. 2012;7(10):e48535.

21. Koike N, et al. Transcriptional architecture and chromatin landscape of the core circadian clock in mammals. Science. 2012;338(6105):349-354.

22. Pizarro A, Hayer K, Lahens NF, Hogenesch JB. CircaDB: a database of mammalian circadian gene expression profiles. Nucleic Acids Res. 2013;41(Database issue):D1009-D1013.

23. Li S, et al. CGDB: a database of circadian genes in eukaryotes. Nucleic Acids Res. 2017;45(D1):D397-D403.

24. Hirota K, Semenza GL. Regulation of hypoxiainducible factor 1 by prolyl and asparaginyl hydroxylases. Biochem Biophys Res Commun. 2005;338(1):610-616.

25. Koyasu S, Kobayashi M, Goto Y, Hiraoka M, Harada H. Regulatory mechanisms of hypoxiainducible factor 1 activity: two decades of knowledge. Cancer Sci. 2018;109(3):560-571.

26. Ayrapetov MK, et al. Activation of Hifl $\alpha$ by the prolylhydroxylase inhibitor dimethyoxalyglycine decreases radiosensitivity. PLoS One. 2011;6(10):e26064.

27. Tous M, Ferré N, Camps J, Riu F, Joven J. Feeding apolipoprotein E-knockout mice with cholesterol and fat enriched diets may be a model of non-alcoholic steatohepatitis. Mol Cell Biochem. 2005;268(1-2):53-58.

28. Schierwagen R, et al. Seven weeks of Western diet in apolipoprotein-E-deficient mice induce metabolic syndrome and non-alcoholic steato- 
hepatitis with liver fibrosis. Sci Rep. 2015;5:12931.

29. Josekutty J, Iqbal J, Iwawaki T, Kohno K, Hussain MM. Microsomal triglyceride transfer protein inhibition induces endoplasmic reticulum stress and increases gene transcription via Ire1 $\alpha$ / cJun to enhance plasma ALT/AST. J Biol Chem. 2013;288(20):14372-14383.

30. Pan X, Hussain MM. Diurnal regulation of microsomal triglyceride transfer protein and plasma lipid levels. J Biol Chem. 2007;282(34):24707-24719.

31. Pan X, Hussain MM. Clock is important for food and circadian regulation of macronutrient absorption in mice. J Lipid Res. 2009;50(9):1800-1813.

32. Mesarwi OA, Shin MK, Bevans-Fonti S, Schlesinger C, Shaw J, Polotsky VY. Hepatocyte hypoxia inducible factor- 1 mediates the development of liver fibrosis in a mouse model of nonalcoholic fatty liver disease. PLoS One. 2016;11(12):e0168572.

33. Semenza GL. Hypoxia-inducible factors in physi- ology and medicine. Cell. 2012;148(3):399-408.

34. Liu Y, et al. HIF- $1 \alpha$ and HIF-2 $\alpha$ are critically involved in hypoxia-induced lipid accumulation in hepatocytes through reducing PGC- $1 \alpha-$ mediated fatty acid $\beta$-oxidation. Toxicol Lett. 2014;226(2):117-123.

35. Hansen HH, Feigh M, Veidal SS, Rigbolt KT, Vrang N, Fosgerau K. Mouse models of nonalcoholic steatohepatitis in preclinical drug development. Drug Discov Today. 2017;22(11):1707-1718.

36. Chen K, Ma J, Jia X, Ai W, Ma Z, Pan Q. Advancing the understanding of NAFLD to hepatocellular carcinoma development: from experimental models to humans. Biochim Biophys Acta Rev Cancer. 2019;1871(1):117-125.

37. Zhang D, et al. The hepatic BMAL1/AKT/ lipogenesis axis protects against alcoholic liver disease in mice via promoting PPAR $\alpha$ pathway. Hepatology. 2018;68(3):883-896.

38. Pan X, et al. Circadian regulation of intestinal lipid absorption by apolipoprotein AIV involves forkhead transcription factors A2 and $\mathrm{O} 1$ and microsomal triglyceride transfer protein. J Biol Chem. 2013;288(28):20464-20476.

39. Kutteh WH, Rainey WE, Carr BR. Glucocorticoids inhibit lipopolysaccharide-induced production of tumor necrosis factor-alpha by human fetal Kupffer cells. JClin Endocrinol Metab. 1991;73(2):296-301.

40. Sunman JA, Hawke RL, LeCluyse EL, Kashuba AD. Kupffer cell-mediated IL-2 suppression of CYP3A activity in human hepatocytes. Drug Metab Dispos. 2004;32(3):359-363.

41. Irani S, Pan X, Peck BC, Iqbal J, Sethupathy P, Hussain MM. MicroRNA-30c mimic mitigates hypercholesterolemia and atherosclerosis in mice. J Biol Chem. 2016;291(35):18397-18409.

42. Soh J, Iqbal J, Queiroz J, Fernandez-Hernando C, Hussain MM. MicroRNA-30c reduces hyperlipidemia and atherosclerosis in mice by decreasing lipid synthesis and lipoprotein secretion. Nat Med. 2013;19(7):892-900. 